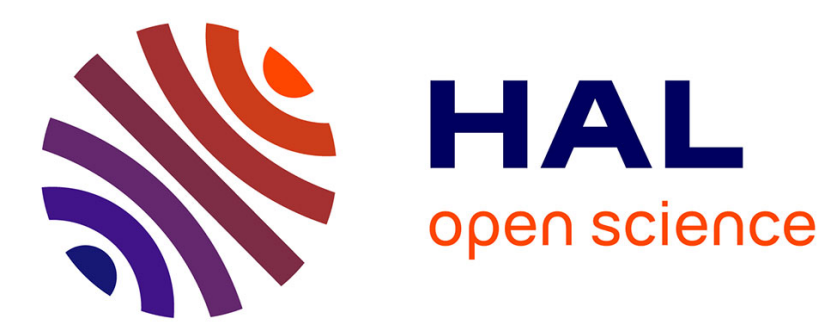

\title{
Increasing the Resolution of Ocean pCO Maps in the South Eastern Atlantic Ocean Merging Multifractal Satellite-Derived Ocean Variables
}

Ismael Hernández-Carrasco, Véronique Garçon, Joël Sudre, Christoph Garbe, Hussein Yahia

\section{To cite this version:}

Ismael Hernández-Carrasco, Véronique Garçon, Joël Sudre, Christoph Garbe, Hussein Yahia. Increasing the Resolution of Ocean pCO Maps in the South Eastern Atlantic Ocean Merging Multifractal Satellite-Derived Ocean Variables. IEEE Transactions on Geoscience and Remote Sensing, 2018, pp.1 - 15. 10.1109/TGRS.2018.2840526 . hal-01825810

\section{HAL Id: hal-01825810 https://hal.inria.fr/hal-01825810}

Submitted on 28 Jun 2018

HAL is a multi-disciplinary open access archive for the deposit and dissemination of scientific research documents, whether they are published or not. The documents may come from teaching and research institutions in France or abroad, or from public or private research centers.
L'archive ouverte pluridisciplinaire $\mathbf{H A L}$, est destinée au dépôt et à la diffusion de documents scientifiques de niveau recherche, publiés ou non, émanant des établissements d'enseignement et de recherche français ou étrangers, des laboratoires publics ou privés. 


\title{
Increasing the Resolution of Ocean $\mathrm{pCO}_{2}$ Maps in the South Eastern Atlantic Ocean Merging Multifractal Satellite-Derived Ocean Variables
}

\author{
Ismael Hernández-Carrasco ${ }^{\circledR}$, Véronique Garçon, Jöel Sudre, Christoph Garbe, and Hussein Yahia
}

\begin{abstract}
A new methodology has been developed in order to improve the description of the spatial and temporal variability of not well-resolved oceanic variables from other well-observed high-resolution oceanic variables. The method is based on the cross-scale inference of information, incorporating the common features of different multifractal high-resolution variables into a coarser one. An exercise of validation of the methodology has been performed based on the outputs of coupled physicalbiogeochemical Regional Ocean Modeling System adapted to the eastern boundary upwelling systems at two spatial resolutions. Once the algorithm has been proved to be effective in increasing the spatial resolution of modeled partial pressure of $\mathrm{CO} 2$ at the surface ocean $\left(\mathrm{pCO}_{2}\right)$, we have investigated the capability of our methodology when it is applied to remote sensing data, focusing on the improvement of the temporal description. In this regard, we have inferred daily $\mathrm{pCO}_{2}$ maps at high resolution $\left(4 \mathrm{~km}\right.$, i.e., $\left.1 / 24^{\circ}\right)$ fusing monthly $\mathrm{pCO}_{2}$ data at low resolution $\left(100 \mathrm{~km}\right.$, i.e., $\left.1^{\circ}\right)$ with the small-scale features contained in daily high-resolution maps of satellite sea surface temperature and Chlorophyll-a. The algorithm has been applied to the South Eastern Atlantic Ocean opening the possibility to obtain an accurate quantification of the $\mathrm{CO}_{2}$ fluxes in relevant coastal regions, such as the eastern boundary upwelling systems. Outputs of our algorithm have been compared with in situ measurements, showing that daily maps inferred from monthly products are in average $6 \mu \mathrm{atm}$ closer to the in situ values than the original coarser monthly maps. Furthermore, values of $\mathrm{pCO}_{2}$ have been improved in points close to the coast with respect to the original input data.
\end{abstract}

Index Terms-Chaos, $\mathrm{CO}_{2}$, fractals, fronts, geophysical signal processing, multifractality, nonlinear dynamical systems, satellite image reconstruction, sea-air interface, singularity exponents, upwelling systems, wavelet transforms.

Manuscript received September 14, 2017; revised April 2, 2018; accepted May 8, 2018. This work was supported by the European Space Agency through the OceanFlux-Upwelling Theme (Science Element) under Grant 400014715/11/I-NB. The work of I. Hernandez-Carrasco was supported by the Spanish Government through the Juan de la Cierva Contract. (Corresponding author: Ismael Hernández-Carrasco.)

I. Hernández-Carrasco is with the Balearic Islands Coastal Observing System, 07122 Palma, Spain (e-mail: ismaelhe@gmail.com).

V. Garçon and J. Sudre are with the Laboratoire d'Etudes en Géophysique et Océanographie Spatiales, Centre National d'Etudes Spatiales-Centre National de la Recherche Scientifique-L'Institut de Recherche pour le Développement-Université Paul Sabatier, 31400 Toulouse, France.

C. Garbe is with the Interdisciplinary Center for Scientific Computing, University of Heidelberg, 69120 Heidelberg, Germany.

H. Yahia is with the Institut National de Recherche en Informatique et en Automatique, 78153 Bordeaux, France.

Color versions of one or more of the figures in this paper are available online at http://ieeexplore.iee.org.

Digital Object Identifier 10.1109/TGRS.2018.2840526

\section{INTRODUCTION}

$\mathbf{G}$ LOBAL change is leading to large-scale changes in climate patterns, ocean circulation, and stratification, while increased atmospheric $\mathrm{CO}_{2}$ levels are leading to ocean acidification of the ocean with severe impacts on marine ecosystems. The lack of data of partial pressure of $\mathrm{CO} 2$ at the surface ocean $\left(\mathrm{pCO}_{2}\right)$, and $\mathrm{CO}_{2}$ fluxes at the air-sea interface at high spatial and temporal resolutions prevents an accurate estimation of the ocean contribution to the global $\mathrm{CO}_{2}$ balance and, therefore, a detailed study of the mechanisms involved in the $\mathrm{CO}_{2}$ interchange. Thus, alternative approaches for inferring the fluxes at high resolution from satellite imagery are needed. Other oceanic variables that have been measured at high resolution and share common structure features with $\mathrm{pCO}_{2}$ might be used to improve the description of the spatial and temporal variability of the air-sea $\mathrm{CO}_{2}$ fluxes.

On this point, new interesting multiscale processing techniques for complex satellite signals have emerged recently [1] with the aim of fusing information of different physical intensive variables at different scales. These methods are developed in the case of fully developed turbulence (FDT) and apply to ocean dynamics because of the high value of Reynolds number in that system. In a turbulent flow, such as the ocean flow, the large dynamical structures (mesoscale eddies) interact with each other generating small-scale structures (filaments and transition fronts) characterized by strong tracer gradients [2], [3]. This results in a cascade of energy from the larger to the smaller scales within the bounds of a well-defined inertial range. The relationship between the multifractal hierarchy and the multiplicative cascade, as previewed in [4], can be attained in the so-called microcanonical multifractal formalism (MMF) (see [5], [6]). Coherent structures and their boundaries can be determined from the singularity exponents (SEs), as well as the multifractal hierarchy. The exponents allow, through wavelet decomposition, the determination, at good accuracy, of an approximation of optimal cascade inference along the scales (the exact determination of such an optimal inference being yet not presently attainable). SEs unlock the multiscale geometric hierarchy associated with FDT, and their use in the analysis of complex data in satellite imagery is a key novel advance of nonlinear signal processing to be developed in this and other studies. The generality of the approach offers the opportunity to infer different oceanic signals from low resolution to high resolution. 
The nonlinear cross-scale inference methodology has been successfully used in the oceanic context, for instance, to merge satellite data obtained at different spatial resolutions [7], obtain ocean currents at high resolution [8], infer spatial super-resolution maps of $\mathrm{pCO}_{2}$ [9], and more recently increase the spatial resolution of sea surface salinity from SMOS [10]. In this paper, we apply these techniques focusing on the increase of the time resolution in the reconstruction of daily maps at higher spatial resolution (resolving submesoscale features) of the $\mathrm{pCO}_{2}$ from monthly climatology products obtained from observations. Other efforts for reconstructing $\mathrm{pCO}_{2}$ values from remote sensing images have been addressed using other linear and nonlinear empirical methods [11]-[13].

The currently existing remote sensing observations of $\mathrm{pCO}_{2}$ are derived from two satellite spectrometers, Greenhouse gases Observing SATellite (GOSAT) and SCanning Imaging Absorption SpectroMeter for Atmospheric CHartographY (SCIAMACHY). Although coastal waters have been alternately reported as globally important sources or sinks of atmospheric $\mathrm{CO}_{2}$ [14], [15], an improved observation system is needed to perform a detailed regional characterization. However, the scarcity of GOSAT and SCIAMACHY observations in the upwelling regions together with their low spatial resolution prevents from obtaining an accurate assessment and evolution of coastal $\mathrm{CO}_{2}$ contribution to the atmosphere.

In a previous study [9], this new methodology was used to reconstruct maps of $\mathrm{pCO}_{2}$ only focusing on the increase of the spatial resolution from remote sensing data. Here, in this paper, we further analyze how the microcanonical cascade methodology can be used to produce daily maps of $\mathrm{pCO}_{2}$ increasing the temporal resolution from monthly climatological products. The methodology has also been further validated using outputs of a coupled Regional Ocean Modeling System (ROMS) with a biogeochemical numerical simulation at two resolutions. In addition, we have analyzed the ability of this method to improve data in coastal areas, where upwelling processes become important, i.e., in the eastern boundary upwelling system of Benguela. Also, a further mathematical description of the theoretical framework for the multiscale methodology has been provided in Section III.

The great potential of this paper lies in the innovative methodology developed to increase the spatial and the temporal resolution of products derived from observations in order to build higher resolution of daily oceanic $\mathrm{pCO}_{2}$ maps improving the coverage in coastal regions. It will allow to infer climatically relevant greenhouse gas (such as sea-air $\mathrm{CO}_{2}$ fluxes) at unprecedented spatial and temporal resolution and, thus, to obtain a more detailed description of the regional mechanisms related to the ocean acidification.

\section{DATA}

We first use data from an ROMS-bio eastern boundary upwelling systems (BioEBUS) coupled model to perform a preliminary validation analysis of the method. Then, we applied the methodology to satellite data at high resolution of oceanic variables: sea surface temperature (SST), ocean color (OC), in conjunction with air-sea $\mathrm{CO}_{2}$ fluxes and oceanic $\mathrm{pCO}_{2}$ at low resolution. Finally, we use oceanic $\mathrm{pCO}_{2}$ in situ measurements to perform the validation analysis of the inference from satellite images.

\section{A. ROMS-BioEBUS Model}

A first evaluation of the method is addressed using data from a coupled physical/biogeochemical simulation model adapted to the eastern boundary upwelling systems (ROMS-BioEBUS). ROMS is a free surface, hydrostatic, and primitive equation model, and the run used here was eddy resolving and climatologically forced [16]. The numerical model was run onto two different grids: a coarse one at a spatial resolution of $1 / 4^{\circ}$ and a finer one at $1 / 12^{\circ}$. This dual-spatial resolution simulation makes it an ideal model for the basis of our methodology in working at two spatial resolutions. BioEBUS has been developed for the Benguela to simulate the first trophic levels of the Benguela upwelling ecosystem functioning and also to include a more detailed description of the complete nitrogen cycle, including denitrification and anammox processes as well as the oxygen cycle and the carbonate system.

\section{B. Satellite High-Resolution Input Data: Chlorophyll-a and Sea Surface Temperature}

The oceanic biological pump and physical pump control the $\mathrm{CO}_{2}$ flux at the air-sea interface and ultimately the role played by the ocean in absorbing atmospheric $\mathrm{CO}_{2}$. The biological pump is driven by upper ocean biological activity and exports to the deep ocean, while physical mixing and vertical circulation in the ocean together with solubility drive the physical pump. In this paper, we develop the algorithm to link oceanic $\mathrm{pCO}_{2}$ to high-resolution remotely sensed SST data as a proxy of the physical pumping and Chlorophyll-a (Chl-a) data as a proxy for the biological pump. In a previous work [9], the use of different products of SST and Chl-a as the input data in our methodology was examined in order to reduce the impact of the low coverage due to cloudiness without degrading the information contained in the small scales. It was found that using merged products, i.e., Chl-a from GLOBCOLOUR (http://www.globcolour.info/CDR_Docs/GlobCOLOUR_PUG. pdf) and SST from the Operational SST and Sea Ice Analysis system (OSTIA) product, the algorithm yields the best results, and therefore, we have chosen such combination for this paper.

We used Chl-a data concentrations derived from the GLOBCOLOUR product. They are obtained through a merging algorithm applied to data provided by Moderate Resolution Imaging Spectroradiometer, Medium Resolution Imaging Spectrometer Instrument, and Sea-Viewing Wide Field-of-view Sensor instruments. We choose the Garver-Siegel-Maritorena version of GLOBCOLOUR derived product. The algorithm produces daily Chl-a maps at the spatial resolution equal to $1 / 24^{\circ}(\sim 4 \mathrm{~km})$. In this paper, we have regridded the data at $1 / 32^{\circ}$ by linear interpolation. More information of GLOBCOLOUR products can be found in Guide document in the link mentioned earlier. We have used 
a common grid with a spatial resolution of $1 / 32^{\circ}$, since the algorithm was originally configured to be applied to every global satellite product, including those at this resolution. When we interpolate to a finer grid, we are not winning effective resolution, but this is just a computation setting in order to have an agreement between the grids of the variables used in the inferring processes.

With regard to SST, we used daily maps at high spatial resolution from the OSTIA data provided by the Group for High-Resolution SST Project. This product is a new analysis of SST that combines the measurements of SST from satellite and in situ observations that come from ships and buoys to determine the SST with a global coverage and without missing data. The product uses a multiscale interpolation using correlation length scales from 10 to $100 \mathrm{~km}$ to produce a daily data set at $1 / 20^{\circ}(5 \mathrm{~km})$. More details can be found in [17], and data can be downloaded from http://www.ncof.co.uk/OSTIADaily-Sea-Surface-Temperature-and-Sea-Ice.html. Fig. 15(a) and (b) shows an example of Chl-a field derived from GSM GLOBCOLOUR and SST from OSTIA, respectively.

\section{Low-Resolution Input Data: Monthly Oceanic pCO $\mathrm{CO}_{2}$}

The data of oceanic $\mathrm{pCO}_{2}$ available from observations in the eastern Benguela upwelling system is a $1^{\circ} \times 1^{\circ}$ monthly product climatology, and no daily $\mathrm{pCO}_{2}$ product is yet available. Therefore, we decided to investigate the effect of using monthly $\mathrm{pCO}_{2}$ at low resolution for the inference of daily super-resolution ocean $\mathrm{pCO}_{2}$. In this paper, we use two different monthly products of $\mathrm{pCO}_{2}$ : one obtained from monthly averages of daily CarbonTracker $\mathrm{pCO}_{2}$ (from now on referred as monthly CT2013 or $\mathrm{pCO}_{2}^{\text {Ctrack }}$ ) and the second one derived from monthly climatology [18] ocean $\mathrm{pCO}_{2}$ product (from now on C-Takahashi or $\mathrm{pCO}_{2}^{\text {Takah }}$ ).

1) CarbonTracker: CarbonTracker provides a global estimation of daily maps of $\mathrm{CO}_{2}$ fluxes at the air-sea interface at the spatial resolution of $1^{\circ}$ from global atmosphere observations used in a data assimilation system for $\mathrm{CO}_{2}$ [19] (see http://www.esrl.noaa.gov/gmd/ccgg/carbontracker for more details).

Partial pressure of $\mathrm{CO}_{2}$ in the ocean, $p_{\mathrm{CO}_{2}}^{\text {ocean }}$, can be obtained from CarbonTracker fluxes, $F$, through the equation of the net flux at the air-sea interface (further details in [9]) by computing the gas exchange coefficients, $K$, and the gas solubility, $\alpha$.

A postprocessing of the raw data of CarbonTracker fluxes of $\mathrm{CO}_{2}$ in the area of study has been performed in order to reduce the strongly binned character and the strong gradients exhibited across those bins. We use the approach developed in [24] to invert the interfacial fluxes using a simplified inverse problem of atmospheric transport.

2) Takahashi $\mathrm{pCO}_{2}$ Climatology: We use data of monthly climatological mean distribution of surface water $\mathrm{pCO}_{2}$ over the global oceans in the reference year of 2000 reinterpolated at $1^{\circ}$ of spatial resolution from the original Takahashi climatology [18]. The database was constructed using about 3 million measurements of surface water $\mathrm{pCO}_{2}$ and is provided by the Carbon Dioxide Information and Analysis Center, Oak Ridge, National Laboratory. The measurements are inter- polated in space and time solving iteratively the advection diffusion transport equation in the sea surface water using a finite-difference algorithm with a time step of one day through the year of reference (see [25] for more details).

\section{In Situ Measurements of $\mathrm{pCO}_{2}$ in Benguela Upwelling System}

The in situ data used to validate our experiments are taken from Surface Ocean CO2 Atlas, version 5 (http://www. socat.info/). This is a database that compiles oceanographic transects from 1967 to 2011 [26]. In our region of interest and for the period of study, we find a total of 16 cruises distributed among the years 2006 (QUIMA2006) and 2008 (QUIMAVOS2008). All the cruises follow the same track in the region extended between $5^{\circ} \mathrm{S}$ and $35^{\circ} \mathrm{S}$ and $6^{\circ} \mathrm{E}$ and $18^{\circ} \mathrm{E}$, and have been analyzed in [27] and [28].

\section{Multiscale Method}

The basic idea is to use the approximation of optimal cascading to decrease the spatial resolution of physical variables. For that matter, we make use of high-resolution SEs of $\mathrm{pCO}_{2}$ obtained from a multilinear regression of a combination of high-resolution SST and Chl-a images, then use the signal available at low resolution of $\mathrm{pCO}_{2}$, and transmit that information along the scales back to higher spatial resolution using the cascade; in the end, we obtain a high-resolution signal of $\mathrm{pCO}_{2}$. The method, based on the MMF [6], uses SEs to derive multiscale properties in SST, Chl-a, and $\mathrm{pCO}_{2}$ signals. The multifractal property of SST, Chl-a, and $\mathrm{pCO}_{2}$ is used to find a simple functional dependence between their corresponding SEs. The algorithm used in this paper to obtain a super-resolution $\mathrm{pCO}_{2}$ is described in [9]; nevertheless, some complementary details describing the methodology-required by the peculiar properties of the physical variables involved in this paper-are given in the following.

\section{A. Microcanonical Transitions Fronts: Singularity Exponents}

A common feature evidenced in the ocean is the multifractal character of many physical variables describing its state. This is due to the turbulent nature of the ocean motion and its associated cascade of energy from large to small scales, which produces a multifractal hierarchy of structures. From complex systems theory, it is known that fractal sets have an intrinsic scale-invariant property that can be expressed by a common fractal dimension: all points in such systems scale according to the value of that dimension. Multifractal systems are a generalization of a fractal system in which a single dimension is not enough to describe the dynamics; instead, a continuum of fractal dimensions, $D(h)$, better describes such a system, leading to the notion of singularity spectrum $h \rightarrow D(h)$, where $D(h)$ is the Hausdorff dimension of the set of points having a common scaling exponent $h$. These exponents can be determined from several approaches. The classical approach to multifractal systems is a statistical one based on the global characterization of some scale-invariant quantities, and in this case, the FDT is explained by means of statistical averages of some dynamical quantities. This kind of approach is sometimes called "canonical." On the other hand, the MMF has 
been developed recently to assess the geometric realization of the multiplicative cascade associated with turbulent hydrodynamics and to allow us to assign a local scaling exponent $h(\mathbf{x})$ to each point in the field [5], [29]. In the remote sensing context, this formalism has been applied to estimate missing data in satellite images [7] or in the reconstruction of ocean velocities maps from tracer images such as SST [8]. We use the algorithm described in [30] to estimate the values of $h(\mathbf{x})$. The numerical evaluation of the SEs can be done by means of an appropriate wavelet projection $\mathcal{T}_{\psi}$ acting on the gradient of the variable $s(\mathbf{x})$ as follows:

$$
\mathcal{T}_{\psi}|\nabla s|(\mathbf{x}, r)=\int_{\mathbb{R}^{2}} \mathrm{~d} \mathbf{x}^{\prime}|\nabla s|\left(\mathbf{x}^{\prime}\right) \frac{1}{r^{2}} \psi\left(\frac{\mathbf{x}-\mathbf{x}^{\prime}}{r}\right)
$$

where $\psi$ is a mother wavelet (nonnecessarily admissible) and $r$ represents the scale parameter associated with a ball's radius around the point $\mathbf{x}$. Thus, if the signal $s(\mathbf{x})$ is multifractal, the wavelet projections will depend as a power law on the scale $r$, such that

$$
\mathcal{T}_{\psi}|\nabla s|(\mathbf{x}, r)=\alpha(\mathbf{x}) r^{h(\mathbf{x})+d}+o\left(r^{h(\mathbf{x})+d}\right) \quad(r \longrightarrow 0)
$$

where $h(\mathbf{x})$ is the SE at point $\mathbf{x}$ and $d$ is the dimension of the embedding space ( $d=2$ in the case of satellite images). The $h(\mathbf{x})$ estimates can be obtained from (2) in the form

$$
h(x)=\frac{\log \left(\mathcal{T}_{\psi}|\nabla s|\left(\mathbf{x}, r_{0}\right) /\left\langle\mathcal{T}_{\psi}|\nabla s|\left(\cdot, r_{0}\right)\right\rangle\right)}{\log r_{0}}+o\left(\frac{1}{\log r_{0}}\right)
$$

where $\left\langle\mathcal{T}_{\psi}|\nabla s|\left(\cdot, r_{0}\right)\right\rangle$ is the mean value of the wavelet projection and $o\left(1 / \log r_{0}\right)$ is the correction factor. Normalization takes place so that $r_{0}$ is the scale corresponding to the smallest area element in the image of size $N \times M$ (i.e., the total number of pixels), such as $r_{0}=1 / \sqrt{N \cdot M}$. Small structures, such as fronts and eddies, displayed in the satellite images are underlined by the most singular manifolds, given by the most negative values of $h(x)$ (points with the lowest negative SEs).

Fig. 15(c) and (d) shows some examples of the SEs of SST and Chl-a images from ROMS-BioEBUS outputs described in Section II-B. The ability of the SEs to unveil the transition fronts hidden in the original images can be appreciated.

Since points with the same value of SE possess the same scaling, we can obtain a multifractal decomposition of the image in the different singularity components (sets of fractals with a different fractal dimension). In this way, the SEs are the basic quantities used to access to the multiscale hierarchy in complex signals.

\section{B. Connection Between Different Oceanic Variables: Multifractality}

The central idea in the methodology is the merging, according to scale, of different physical variables to improve another different variable functionally dependent of the first ones. Therefore, we need to find the oceanic variables related to $\mathrm{pCO}_{2}$ and available at high resolution. It has been shown that phytoplankton plays an important role in the ocean carbon cycle. As seen in Section II-C, as an approximation, we can consider Chl-a as one proxy for the biological pump and temperature as the proxy for the physical and solubility pump. These two variables are available at high resolution, so we selected them to be used in conjunction with the oceanic $\mathrm{pCO}_{2}$.

We assume that $\mathrm{pCO}_{2}$ data possess a multifractal character and therefore such signals are expected to feature cascading, multiscale, and other characteristic properties found in turbulent signals as described in [5] and [6]. This justifies the use of nonlinear and multiscale signal processing techniques to assess the properties of the $\mathrm{pCO}_{2}$ signal across the scales. The multifractal character of $\mathrm{pCO}_{2}$ can be readily verified from model outputs through the computation of singularity spectra (log-histograms of the SE) of $\mathrm{pCO}_{2}$. Experimentation shows that there is a strong correlation (though not identity) of coherent structures of $\mathrm{pCO}_{2}$ and those of the other physical variables involved in the pumps. This property allows us to assume that there is a good correlation between the turbulent transitions given by SEs of physical variables involved and these are good candidates for a multiresolution analysis combining the SE of the three signals SST, Chl-a, and $\mathrm{pCO}_{2}$. These two properties have been demonstrated based in model outputs in Section IV-A.

Therefore, due to the multifractal character of SST, Chl-a, and $\mathrm{pCO}_{2}$, the connection between variables is done through linear regression of their SEs

$$
\begin{array}{r}
\mathcal{S}\left(\mathrm{pCO}_{2}\right)(\mathbf{x})=a(\mathbf{x}) \mathcal{S}(\mathrm{SST})(\mathbf{x})+b(\mathbf{x}) \mathcal{S}(\mathrm{Chl}-a)(\mathbf{x}) \\
+c(\mathbf{x}) \mathcal{S}\left(\mathrm{pCO}_{2}{ }^{\mathrm{LR}}\right)(\mathbf{x})+d(\mathbf{x})
\end{array}
$$

where $a(\mathbf{x}), b(\mathbf{x})$, and $c(\mathbf{x})$ are the regression coefficients associated with the SEs $\mathcal{S}\left(\mathrm{pCO}_{2}\right)(\mathbf{x})$ of $\mathrm{pCO}_{2}$ at $\mathbf{x}, \mathcal{S}(\mathrm{SST})(\mathbf{x})$ of SST at $\mathbf{x}$, and $\mathcal{S}(\mathrm{Chl}-\mathrm{a})(\mathbf{x})$ of Chl-a signal at $\mathbf{x}$. In order to propagate the $\mathrm{pCO}_{2}$ signal itself across the scales in the multiresolution analysis, we introduce $\mathcal{S}\left(\mathrm{pCO}_{2}{ }^{\mathrm{LR}}\right)$ to refer to the $\mathrm{SE}$ from $\mathrm{pCO}_{2}$ at low resolution interpolated on the highresolution grid; $d(\mathbf{x})$ is the error associated with the multiplelinear regression.

We use the outputs of the ROMS-BioEBUS model developed for the Benguela upwelling system (II-A) to estimate the regression coefficients. Note that all variables and coefficients matrices have to be regridded to the one with the highest resolution in order to have the same size.

The result of the linear combination of the SEs of the different oceanic variables is a proxy of oceanic $\mathrm{pCO}_{2}$ data at high resolution, which can be used in the multiscale analyses to know how the information is transmitted across the scales between the $\mathrm{pCO}_{2}$ at low and high resolution.

\section{Propagation of Information Across the Scales}

In multifractal systems, the scaling properties are analyzed by means of wavelets. Wavelets allow the projection of a multiscale signal at different, well-defined scales. Different wavelets lead to diverse localization effects in temporal and/or spatial frequencies, which can become crucial for the identification of scale-dependent directional interactions. For this reason, not all multiresolution analyses are equivalent. In our case, where information is to be propagating along the scales from low resolution to high resolution, we are interested in the wavelet 
that propagates information across the scales [1], [31] in a way close to optimal.

If we have two different scales $r_{1}$ and $r_{2}\left(r_{1}<r_{2}\right)$ and a signal $s$ of ocean $\mathrm{pCO}_{2}$ with a multifractal hierarchic structure, the microcanonical cascade relation associated with the dissipation of energy across scales can be determined by wavelets' projections of the signal $\mathcal{T}_{\psi}\left(\mathrm{pCO}_{2}\right)$ in the following form:

$$
\mathcal{T}_{\psi} \mathcal{S}\left(\mathrm{pCO}_{2}\right)\left(\mathbf{x}, r_{1}\right)=\eta_{r_{1} / r_{2}}(\mathbf{x}) \mathcal{T}_{\psi} \mathcal{S}\left(\mathrm{pCO}_{2}\right)\left(\mathbf{x}, r_{2}\right)
$$

where $\eta_{r_{1} / r_{2}}(\mathbf{x})$ is the cascade variable and the wavelet projection of the signal in a basis of proper family of wavelets $\psi_{x_{n}, r_{j}}$ (derived from a mother wavelet $\Psi$ ) is given by

$$
\mathcal{T}_{\psi} \mathcal{S}\left(\mathrm{pCO}_{2}\right)\left(\mathbf{x}, \mathbf{r}_{j}\right)=\sum_{n \in \mathbb{Z}}\left\langle\mathcal{S}\left(\mathrm{pCO}_{2}\right) \mid \psi_{x_{n}, r_{j}}\right\rangle \psi_{x_{n}, r_{j}}(u)
$$

The process of energy injection $\eta_{r_{1} / r_{2}}(\mathbf{x})$ across the scales is independent of $\mathcal{T}_{\psi} \mathcal{S}\left(\mathrm{pCO}_{2}\right)(\mathbf{x}, \mathbf{r})$. Moreover, the injection of energy or the information along the scales takes place in the multiscale hierarchy that is accessible by the local SEs in the microcanonical framework

$$
\mathcal{F}_{h}=\{\mathbf{x}: h(\mathbf{x})=h\}
$$

and, in particular, a set of points that are the most unpredictable are the points with the smallest values of the SEs, and corresponding to the geometrical place in the signal where the transitions are the strongest

$$
\mathcal{F}_{\infty}=\left\{\mathbf{x}: h(\mathbf{x})=h_{\infty}=\min (h(\mathbf{x}))\right\} .
$$

In the multiresolution analysis, we use the classical dyadic scheme and the mother wavelet representation by the BattleLemarie 3-41. There are evidences that such an optimal wavelet exists in marine turbulence [7] for the specific case of wavelet dyadic representation of the cascade. For a wavelet near to optimal wavelet, it is possible to obtain the parent and child coefficients, $\alpha_{p}$ and $\alpha_{c}$, respectively, and thereby the injection cascade variable as follows:

$$
\eta_{r_{1} / r_{2}}(\mathbf{x})=\frac{\alpha_{p}(\mathbf{x})}{\alpha_{c}(\mathbf{x})} .
$$

After the multiresolution analysis, we have the coefficients to propagate the microcanical cascade information in the signal data across the scales. Then, we apply the cascade directly on the low-resolution $\mathrm{pCO}_{2}$ signal to finally derive the superresolution $\mathrm{pCO}_{2}$ field.

\section{Optimization: Sensitivity Analysis}

Further study has been performed on refining the multiscale methodology itself. Since the regression coefficients $a(x)$, $b(x), c(x)$, and $d(x)$ of (4) are the degree of dependence on each physical and biological variable, it is important to perform a sensitivity study with different types of coefficients in order to analyze the robustness of the methodology. As a target, the generation of constant values over time and space and seasonal climatologies for the $a(x), b(x)$, and $c(x)$ coefficients has been explored. In previous studies (see [9]), the regression coefficients are obtained computing the multiple-linear regression in each pixel over 10 years of ROMS BioEBUS simulation outputs data. In this case,
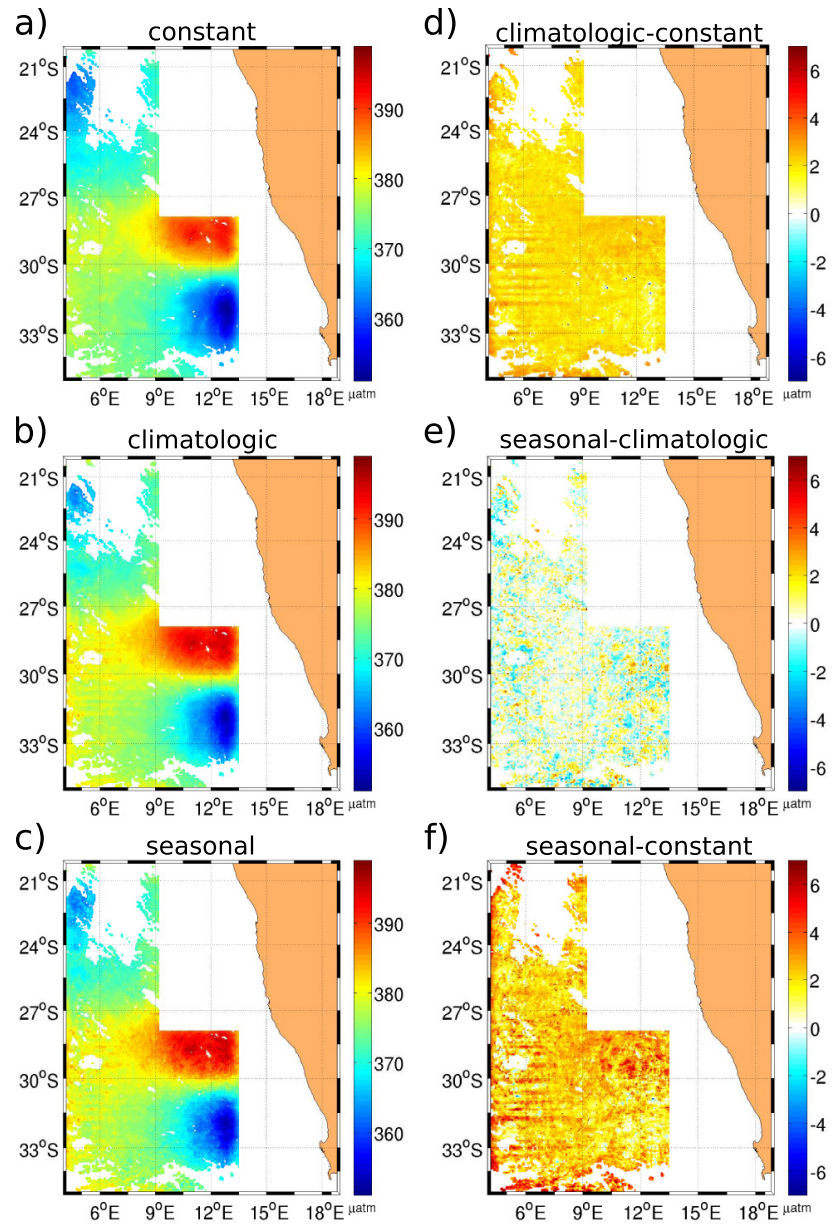

Fig. 1. Maps of inferred $\mathrm{pCO}_{2}$ corresponding to May 15, 2008, using (a) constant, (b) climatological coefficients, and (c) seasonal correlation coefficients. (d) Difference between the reconstructed $\mathrm{pCO}_{2}$ using climatological (b) and using constant correlation coefficients (a). (e) Difference between the inferred $\mathrm{pCO}_{2}$ using seasonal (c) and climatological (b) correlation coefficients. (f) Difference between the inferred $\mathrm{pCO}_{2}$ using seasonal (c) and constant (a) correlation coefficients.

we obtain regression coefficients independent of time and dependent on the spatial position of the pixel. We refer to these regression coefficients as climatological regression coefficients, because their values are constant along the year but different for each spatial point. Fig. 1(b) shows the snapshot of inferred oceanic $\mathrm{pCO}_{2}$ at high resolution using climatological regression coefficients corresponding to May 16, 2008. As a next computation, we propose to use constant regression coefficients, $\bar{a}, \bar{b}, \bar{c}$, and $\bar{d}$, that is, the same value for all the spatial points (pixels) in the field, and given by the spatial average of the climatological regression coefficients over the whole image

$$
\begin{aligned}
& \bar{a}=\frac{1}{N} \sum_{i=1}^{N} a\left(x_{i}\right) ; \quad \bar{b}=\frac{1}{N} \sum_{i=1}^{N} b\left(x_{i}\right) \\
& \bar{c}=\frac{1}{N} \sum_{i=1}^{N} c\left(x_{i}\right) ; \quad \bar{d}=\frac{1}{N} \sum_{i=1}^{N} d\left(x_{i}\right)
\end{aligned}
$$

where $i$ is the index of the pixel and $N$ is the total number of pixels. In this case, the regression coefficients are independent of time and space. 
a)

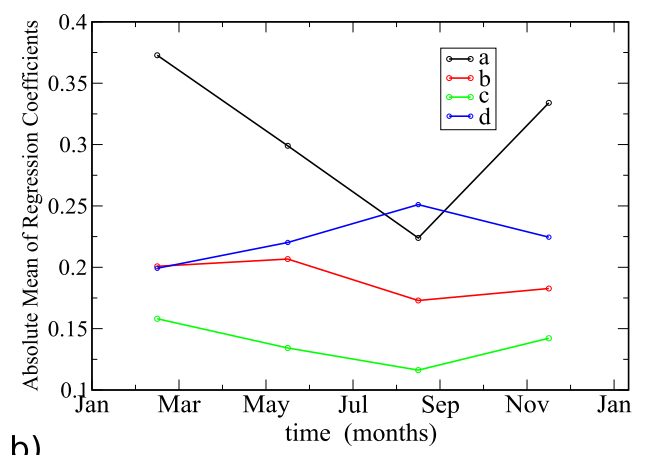

b)

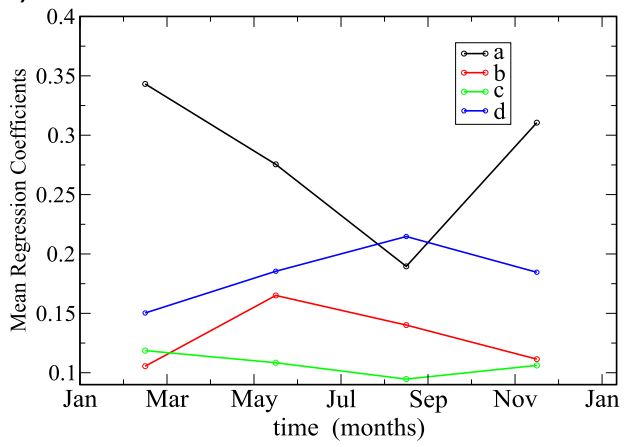

Fig. 2. Evolution of seasonal regression coefficients. (a) Spatial average of the absolute values of the regression coefficients. (b) Spatial average of the values of regression coefficients.

This experiment shows some insights of the importance of the spatial variability of the coefficients in the estimation of the inferred field. An example of the inferred $\mathrm{pCO}_{2}$ using constant values of regression coefficients is shown in Fig. 1(a).

A last experiment is performed to explore the effect of the time dependence of the regression coefficients. To do that, we use seasonal regression coefficients, $a(\mathbf{x}, T)$, $b(\mathbf{x}, T), c(\mathbf{x}, T)$, and $d(\mathbf{x}, T)$, which have been obtained by computing seasonal climatologies of these regression coefficients in each pixel and over the 10 years of ROMS-BioEBUS data. In this case, the regression coefficients are time and space dependent. One snapshot showing the field of the inferred $\mathrm{pCO}_{2}$ using seasonal coefficients is shown in Fig. 1(c). In this figure, one can see that the general pattern in the spatial distribution of the inferred $\mathrm{pCO}_{2}$ values for the three cases of the regression coefficients is rather the same, and only small differences in the details can be observed.

We have computed the difference between maps of inferred $\mathrm{pCO}_{2}$ using the three types of regression coefficients [Fig. 1(d)-(f)]. Larger differences have been found between climatological and constant coefficients and also between seasonal and constant coefficients (approximately $4 \mu \mathrm{atm}$ ). On the other hand, seasonal and climatological coefficients show low differences (in the order of $1 \mu \mathrm{atm}$ ). Also, it can be observed that $\mathrm{pCO}_{2}$ obtained from seasonal and climatological coefficients is larger than when using constant coefficients.

The time evolution of spatial average of regression coefficients is shown in Fig. 2. One can see that the connection between the different oceanic variables is stronger in austral
TABLE I

ME, AE, ANd RE of PCO 2 VAlues Obtained From CARbontracker AND $\mathrm{PCO}_{2}$ VALUES INFERRED AT SUPER-RESOLUTION USING GLOBCOLOUR OC AND OSTIA SST WiTH RESPECT to Values of $\mathrm{PCO}_{2}$ Measurements DuRing The QUIMA2006/QUIMA2008 CRUISES IN THE BENGUELA REgION

\begin{tabular}{|l|c|c|c|}
\hline & Constant & Annual & Seasonal \\
\hline $\mathrm{N}^{\circ}$ valid intersections & 1928 & 1928 & 1928 \\
\hline$M E_{\text {Ctrack }}(\mu a t m)$ & 8.8 & 8.8 & 8.8 \\
\hline$M E_{\text {infer }}(\mu a t m)$ & 3.4 & 3.4 & 2.1 \\
\hline$A E_{\text {Ctrack }}(\mu a t m)$ & 22.1 & 22.1 & 22.1 \\
\hline$A E_{\text {infer }}(\mu a t m)$ & 17.1 & 16.5 & 16.3 \\
\hline$R E_{\text {Ctrack }}$ & 0.06 & 0.06 & 0.06 \\
\hline$R E_{\text {infer }}$ & 0.047 & 0.045 & 0.044 \\
\hline \hline
\end{tabular}

summer and weaker in winter. The connection between the structures of $\mathrm{pCO}_{2}$ with those of Chl-a and SST is more significant during summer, maybe because of the strong upwelling events, and therefore developing more and stronger Chl-a structures. This may produce an increase of the values of the SEs decisive for the cross-scale propagation of information.

In order to obtain an idea of the differences between the inferred $\mathrm{pCO}_{2}$ obtained from the three types of regression coefficients, we have compared the results of the three experiments with in situ measurements of $\mathrm{pCO}_{2}$ taken in Benguela. We quantify the difference between $\mathrm{pCO}_{2}^{\text {infer }}$ values and $\mathrm{pCO}_{2}^{\text {in situ }}$ by computing the errors defined in (11)-(16). We summarize the results of these computations in Table I. The most significant result is that mean errors (MEs) between the inferred $\mathrm{pCO}_{2}$ values with respect to in situ $\mathrm{pCO}_{2}$ measurements are rather the same for the three types of the regression coefficients being slightly smaller for the case of seasonal regressions coefficients and the largest for constant values of regression coefficients.

From these experiments, we can conclude that the improvement of the inferred $\mathrm{pCO}_{2}$ values using seasonal regression coefficients is too moderate to be considered in the next computations. The computational cost of including the seasonal coefficients in the algorithm is too expensive for the small improvement in the $\mathrm{pCO}_{2}$ field, and therefore, we use climatological coefficients for the next computations.

\section{RESUlts}

\section{A. Validation of the Method Based on Model Outputs at Two Resolutions}

In order to validate the methodology, we use an ROMSBioEBUS coupled physical/biogeochemical simulation model (see Section II-A). Fig. 3(a)-(c) shows the ROMS-simulated SST, Chl-a at high resolution, and $\mathrm{pCO}_{2}$ at low resolution output with the results of the computation of their corresponding SEs of the associated SST, Chl-a, and $\mathrm{pCO}_{2}$ at the same date and spatial resolution in Fig. 3(d)-(f), respectively. Fig. 3 clearly shows one of the main ideas implemented in the method: coherent structures of both signals are related, and since the SEs that are dimensionless quantities recording transition strengths in a signal properly encode the multiscale transitions, the multiresolution analysis has to be performed on them instead of the original signals. 

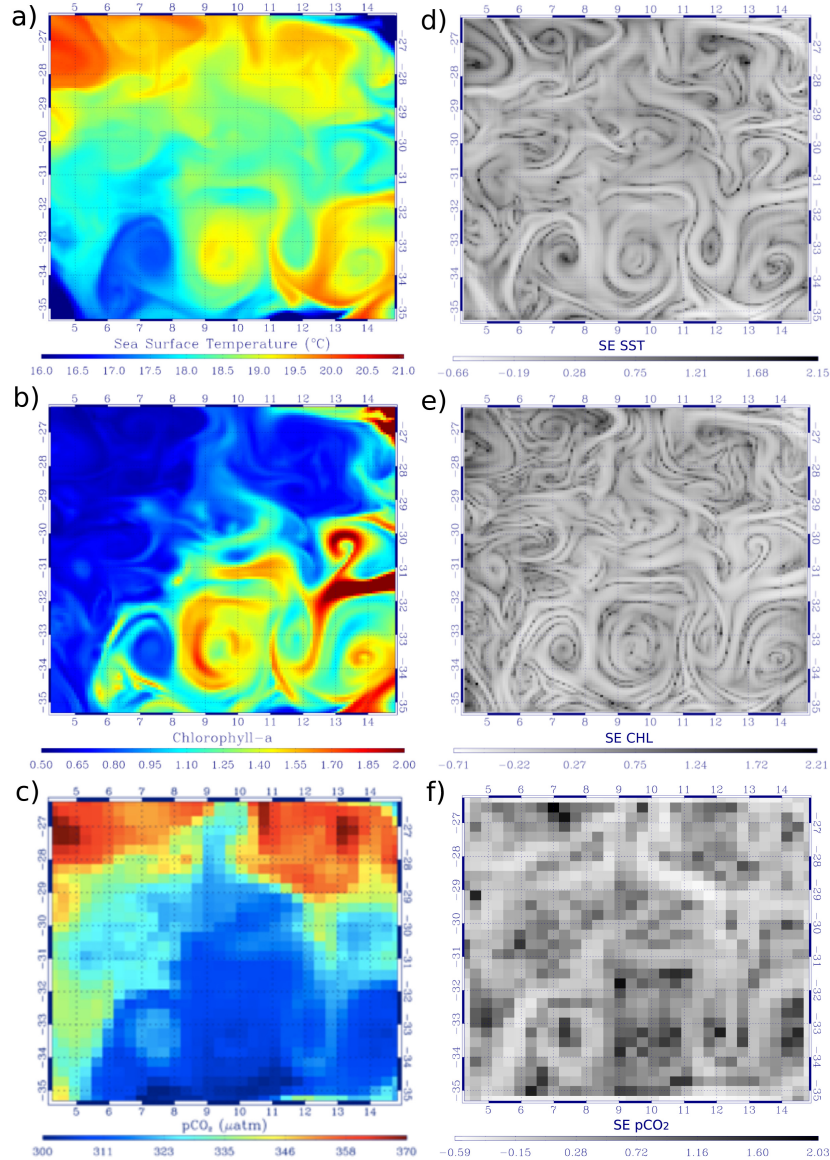

Fig. 3. (Left) Output of ROMS BioEBUS model. (a) SST and (b) Chl-a at high resolution $\left(1 / 12^{\circ}\right)$. (c) $\mathrm{pCO}_{2}$ at low resolution $\left(1 / 4^{\circ}\right)$. (Right) Corresponding SEs of variables plotted in the left.

Since the model provides the outputs of $\mathrm{pCO}_{2}$ signals at two resolutions, we have analyzed the characteristics of the presence of a multiscale organization, related to the cascading properties of intensive variables typical of turbulence, which can be evidenced by studying the singularity spectra [4]-[6]. In this regard, we have computed the singularity spectra for SST [Fig. 4(a)] and oceanic $\mathrm{pCO}_{2}$ [Fig. 4(b)] signal generated by the ROMS BioEBUS simulation model using three years of simulation output with a time step interval of five days at three spatial resolutions: $1 / 12^{\circ}$ (black points), $1 / 6^{\circ}$ (red points), and $1 / 3^{\circ}$ (green points). The singularity spectra for both signals SST and oceanic $\mathrm{pCO}_{2}$ share the general characteristics of turbulent signals, and the shape of the spectra for three different scales suggests strongly the presence of a multiscale structure and consequently justifies a priori the use of nonlinear and multiscale signal processing techniques to assess the properties of the oceanic $\mathrm{pCO}_{2}$ signal across the scales.

As can be guessed from Fig. 3, even if the physical variables $\mathrm{pCO}_{2}$, SST, and CHL-a concentrations are of different kinds, their transitions seem to be correlated in a simple manner. This is analyzed studying the relationship between the normalized $\mathrm{pCO}_{2}$ and SST and Chl-a, and also among their corresponding SEs. Fig. 5(a) and (b) shows the scatter
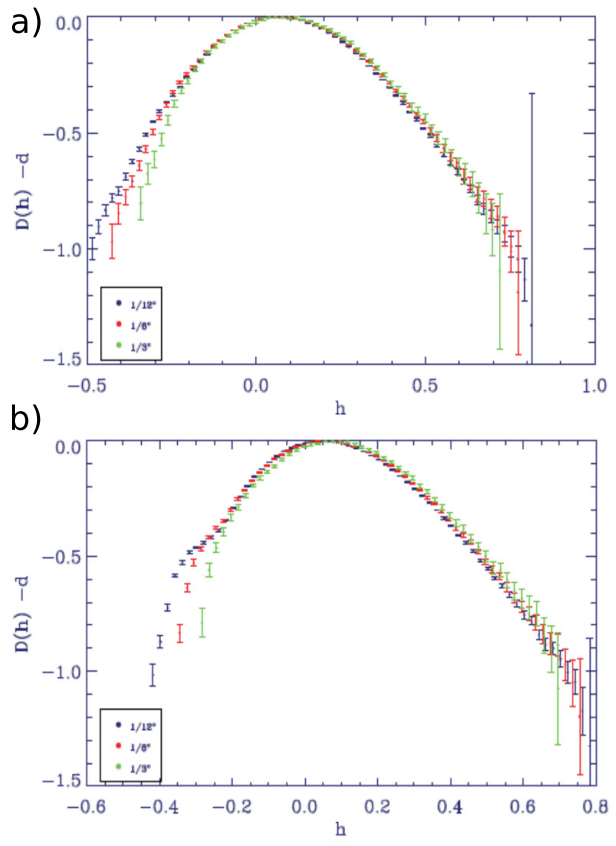

Fig. 4. Singularity spectra of (a) SST and (b) oceanic $\mathrm{pCO}_{2}$ signal generated by the ROMS-BioEBUS simulation model at three spatial resolutions: $1 / 12^{\circ}$ (black points), $1 / 6^{\circ}$ (red points), and $1 / 3^{\circ}$ (green points).
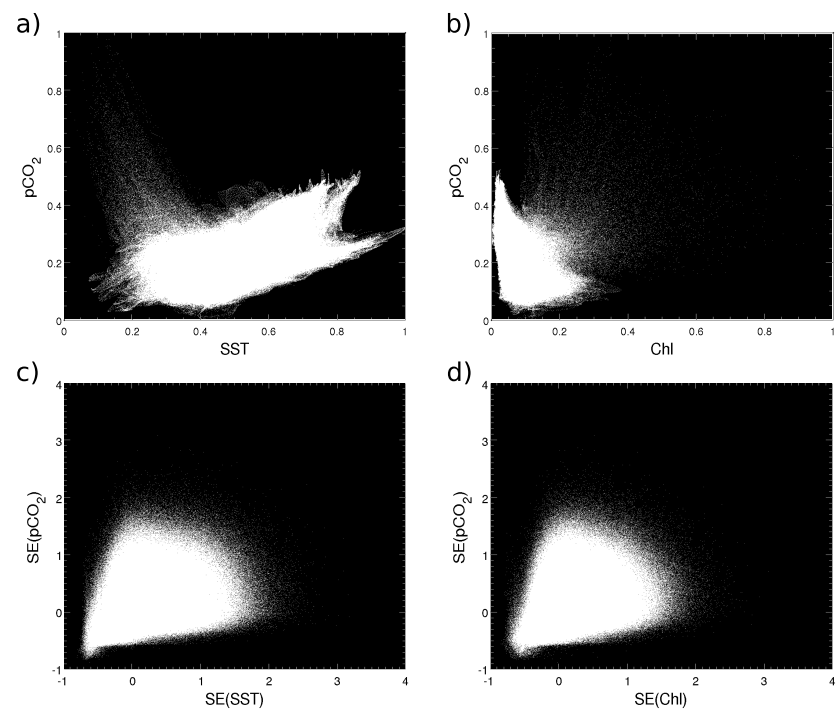

Fig. 5. Scatter plot of (a) normalized $\mathrm{pCO}_{2}$ versus SST, (b) normalized $\mathrm{pCO}_{2}$ versus Chl-a, (c) SEs of $\mathrm{pCO}_{2}$ versus SEs of (SST), and (d) SEs of $\mathrm{pCO}_{2}$ versus $\mathrm{SEs}$ of $\mathrm{Chl}-\mathrm{a}$.

plot of $\mathrm{pCO}_{2}$ versus SST and $\mathrm{pCO}_{2}$ versus Chl-a, respectively. Computations are conducted over a period of 10 years on ROMS-BioEBUS simulated data over the Benguela upwelling region with images corresponding to $128 \times 128$ pixels. There is one data every 10 days. The functional dependence between the original signals that are physical variables of different dimensions is complex and undetermined. On the contrary, the scatter plot of their corresponding SEs [Fig. 5 (c) and (d)] clearly displays a much simpler dependence. One finds that the dimensionless SE of these variables that record the multiscale transitions is approximated at satisfactory precision by 

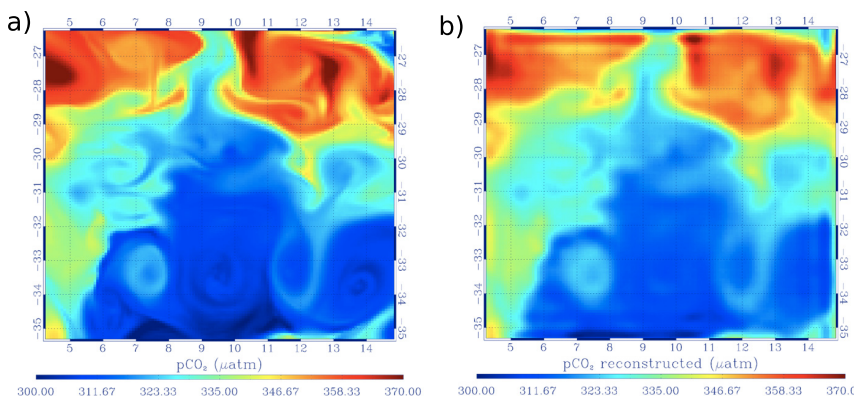

Fig. 6. (a) Original $\mathrm{pCO}_{2}$ at high resolution as simulated by ROMS-BioEBUS high resolution $1 / 12^{\circ}$. (b) Reconstructed $\mathrm{pCO}_{2}$ at high resolution $\left(1 / 12^{\circ}\right.$ ) from the cascade on the low-resolution $\mathrm{pCO}_{2}$ signal $\left(1 / 4^{\circ}\right)$ displayed in Fig. 3(c).

a linear regression. These results show the concept stated in Section III-B that turbulent structures represented by the SEs of these three signals are good candidates to perform the multiscale processing to infer the super-resolution oceanic $\mathrm{pCO}_{2}$ rather than the original oceanic variables.

Next, we introduce the combination of the SE of three signals, such as $\mathrm{pCO}_{2}$ at low resolution, SST, and Chl-a, in (4) to obtain the proxy of the $\mathrm{SE}\left(\mathrm{pCO}_{2}\right)$ at high resolution, which allow to propagate the information along the scales. Fig. 6(b) shows the results of the inferred $\mathrm{pCO}_{2}$ at superresolution obtained by the algorithm, and Fig. 6(a) shows the original high-resolution $\mathrm{pCO}_{2}$ output of the ROMS-BioEBUS model. We compute the mean absolute error (AE) of the $\mathrm{pCO}_{2}$ reconstructed values with respect to the original ROMS simulated $\mathrm{pCO}_{2}$ at high resolution, over a 10 years period (1990 and 2000), obtaining a value equal to $2.4 \mu \mathrm{atm}[0.87 \%$ of relative error $(\mathrm{RE})]$.

These experiments show the good results obtained from our algorithm by propagating a signal across the scales of a multiresolution analysis determined on the critical transitions, i.e., the SE, and therefore their reliability. This tends to indicate that the SEs do encode properly the multiscale hierarchy present in turbulent flows. As a consequence, we consider that a multiresolution analysis performed on the critical transitions, i.e., the $\mathrm{SE}\left(\mathrm{pCO}_{2}\right)$, provides a satisfactory approximation of the microcanonical cascade and is, in practice, equivalent to an optimal multiresolution analysis.

\section{B. Effect of Using Monthly Low Resolution $\mathrm{pCO}_{2}$ on the Inference of Daily Super-Resolution Ocean $\mathrm{pCO}_{2}$}

Once proved the feasibility of reconstructing adequately the high $\mathrm{pCO}_{2}$ signal using dual-ROMS-BioEBUS simulations at various resolutions, we analyze the effect of using monthly $\mathrm{pCO}_{2}$ instead of daily $\mathrm{pCO}_{2}$ at low resolution on the reconstruction of daily ocean $\mathrm{pCO}_{2}$ at high resolution when the input data are derived from satellite images and observations. We use the two different monthly products of $\mathrm{pCO}_{2}$ at low

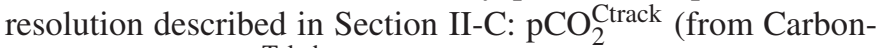
Tracker) and $\mathrm{pCO}_{2}^{\text {Takah }}$ (from Takahashi climatology).

1) Inference of Daily High-Resolution $\mathrm{pCO}_{2}$ Using Monthly Carbontracker Data: We now apply our inference methodology to the low-resolution $\mathrm{pCO}_{2}$ data derived from the new Carbontracker product released in 2013 [19], since
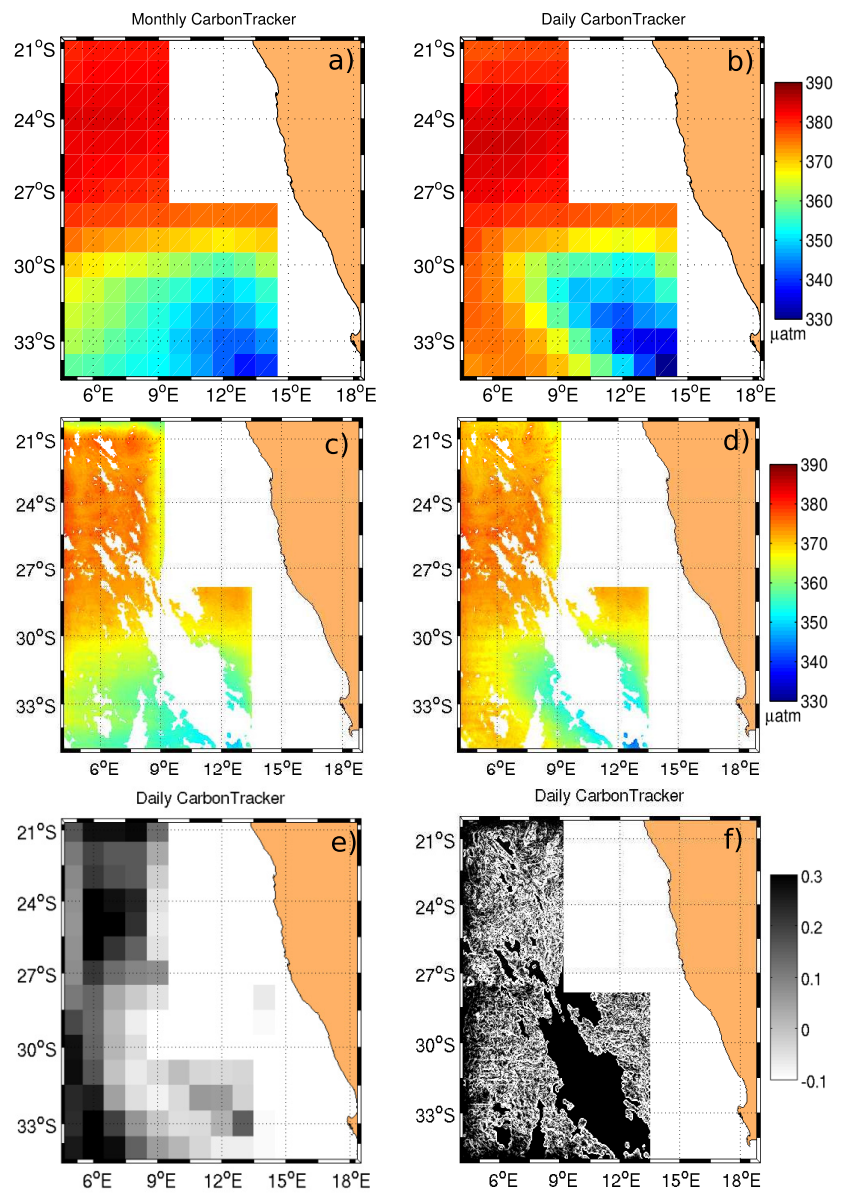

Fig. 7. (a) Monthly average over June 2006 of daily ocean $\mathrm{pCO}_{2}$ derived from CT2013 CarbonTracker data at the spatial resolution of $1^{\circ} \times 1^{\circ}$. (b) Snapshot of $\mathrm{pCO}_{2}$ at low resolution obtained from CT2013 CarbonTracker data for June 7,2006 . (c) Inferred $\mathrm{pCO}_{2}$ at super-resolution $\left(1 / 32^{\circ}\right)$ derived from OSTIA SST, GLOBCOLOUR-GSM Chl-a for June 7, 2006, and monthly low resolution $\mathrm{pCO}_{2}$ plotted in (a) and (d) the same as (c) but using daily $\mathrm{pCO}_{2}$ from daily CarbonTracker data for June 07, 2006. (e) and (f) SEs of the low resolution $\mathrm{pCO}_{2}$ plotted in (b) and the super-resolution $\mathrm{pCO}_{2}$ shown in (d).

this version of Carbontracker yields better results than the older version released in 2011 (not shown). We focus the study on the selected Benguela upwelling regions for the 2006 and 2008 years, when more in situ measurements are available. As already mentioned earlier, for the inference, we use daily SST data from OSTIA and daily OC from GLOBCOLOUR-GSM at high resolution (see Section II-B).

To illustrate the capability of our full algorithm to infer daily high-resolution maps of $\mathrm{pCO}_{2}$ in the Benguela region from monthly low resolution $\mathrm{pCO}_{2}^{\text {Ctrack }}$, an example of daily and monthly $\mathrm{pCO}_{2}^{\text {Ctrack }}$ and daily $\mathrm{pCO}_{2}^{\text {infer }}$ is shown in Fig. 7. We plot the snapshot of the monthly low resolution $\mathrm{pCO}_{2}^{\text {Ctrack }}$ obtained from the monthly average of low-resolution daily $\mathrm{pCO}_{2}^{\text {Ctrack }}$ values over June 2006 derived from daily CarbonTracker $\mathrm{CO}_{2}$ fluxes in Fig. 7(a) and the daily $\mathrm{pCO}_{2}^{\text {Ctrack }}$ derived from daily CarbonTracker in Fig. 7(b) corresponding to June 07, 2006. Fig. 7(c) and (d) shows their corresponding reconstructed daily high-resolution $\mathrm{pCO}_{2}^{\text {infer }}$ for June 07, 2006. Values of daily $\mathrm{pCO}_{2}^{\text {Ctrack }}$ [Fig. 7(a)] are not very different than monthly $\mathrm{pCO}_{2}^{\text {Ctrack }}[$ Fig. 7(b)], and the same happens for 
their corresponding $\mathrm{pCO}_{2}^{\text {infer }}$ [Fig. 7(c) and (d), respectively], exhibiting similar general patterns (with minimum values in the southeastern region and maximum values in northern regions). However, small structures in the high-resolution maps of $\mathrm{pCO}_{2}$ can be appreciated. Furthermore, the map of SEs of the high-resolution inferred $\mathrm{pCO}_{2}$ [Fig. 7(f)] is greatly different to that of the input low resolution $\mathrm{pCO}_{2}$ [Fig. 7(e)], showing the fact that the inferring process is not about smoothing the gradients of the low resolution $\mathrm{pCO}_{2}$, but it is incorporating small-scale features unveiled by the SEs of the SST and Chl-a images. Note that, even only affecting a small number of pixels, the lower values observed in the edge of the inferred $\mathrm{pCO}_{2}$ maps are due to the border effect of the wavelet transform. This effect is common in convolution operations along finite signals. When the signals are over in a finite domain, the wavelet transform requires the computation of nonexistent values outside the domain, creating a border effect, where transform values close to the border of the signal are corrupted by the nonavailable data of the signal limit.

Next, we perform a comparison and validation of the output of our algorithm with in situ data. In this analysis, we use $\mathrm{pCO}_{2}$ ocean data from in situ measurements $\left(\mathrm{pCO}_{2}^{\text {in situ }}\right)$ taken over the Benguela region in the SOCAT version 2 (see Section II-D for more details). An example of the qualitative comparison of values of monthly and daily $\mathrm{pCO}_{2}^{\text {Ctrack }}$, their corresponding $\mathrm{pCO}_{2}^{\text {infer }}$, and $\mathrm{pCO}_{2}^{\text {in situ }}$ at the intersections of the QUIMA cruises during April 26-30, 2006 and July 4-6, 2008 as a function of longitude is shown in Fig. 8 (top) and (bottom), respectively. Values of $\mathrm{pCO}_{2}^{\text {Ctrack }}$ and $\mathrm{pCO}_{2}^{\text {infer }}$ from the daily CarbonTracker data approximate slightly better $\mathrm{pCO}_{2}^{\text {in situ }}$ values than those from monthly CarbonTracker data. Gradients and small-scale fluctuations detected in the longitudinal profile of $\mathrm{pCO}_{2}^{\text {in situ }}$ are also exhibited in the $\mathrm{pCO}_{2}^{\text {infer }}$ profile derived from the monthly $\mathrm{pCO}_{2}$ product at low resolution. This shows that the fronts information contained in the daily high-spatial-resolution maps of SST and Chl-a is well propagated by the cascade in the $\mathrm{pCO}_{2}$ maps for both (monthly and daily) cases. Also, it can be appreciated that the values of the inferred $\mathrm{pCO} 2$ can be larger or smaller than the in situ values. This depends on the combination of the structures captured by the SEs of the SST and Chl-a signals. Likewise, the small-scale features extracted from SEs depend on the quality of the satellite images of SST and Chl-a, i.e., noisy data introduced by the interpolation schemes used to merge data from the different sensors, nominal spatial resolution, missing points due to cloud coverage, failures in sensors software or hardware, and so on.

To quantify the difference between the values of $\mathrm{pCO}_{2}^{\text {Ctrack }}$ and $\mathrm{pCO}_{2}^{\text {infer }}$ for daily and monthly CarbonTracker data with respect to $\mathrm{pCO}_{2}^{\text {in situ }}$ measurements, we compute statistical quantities described in Section V. In general, we find that in most of the cruises (not shown), the $\mathrm{AE}$ for $\mathrm{pCO}_{2}^{\text {Ctrack }}$ and $\mathrm{pCO}_{2}^{\text {infer }}$ is slightly smaller for daily $\mathrm{pCO}_{2}^{\text {Ctrack }}$ than for monthly $\mathrm{pCO}_{2}^{\text {Ctrack }}$. We summarize in the first and second columns of Table II the results of the computations of the errors given by (11)-(16) by making averages over all the intersections of $\mathrm{pCO}_{2}$ values to be validated with the in situ measurements found over 2006 and 2008. A total
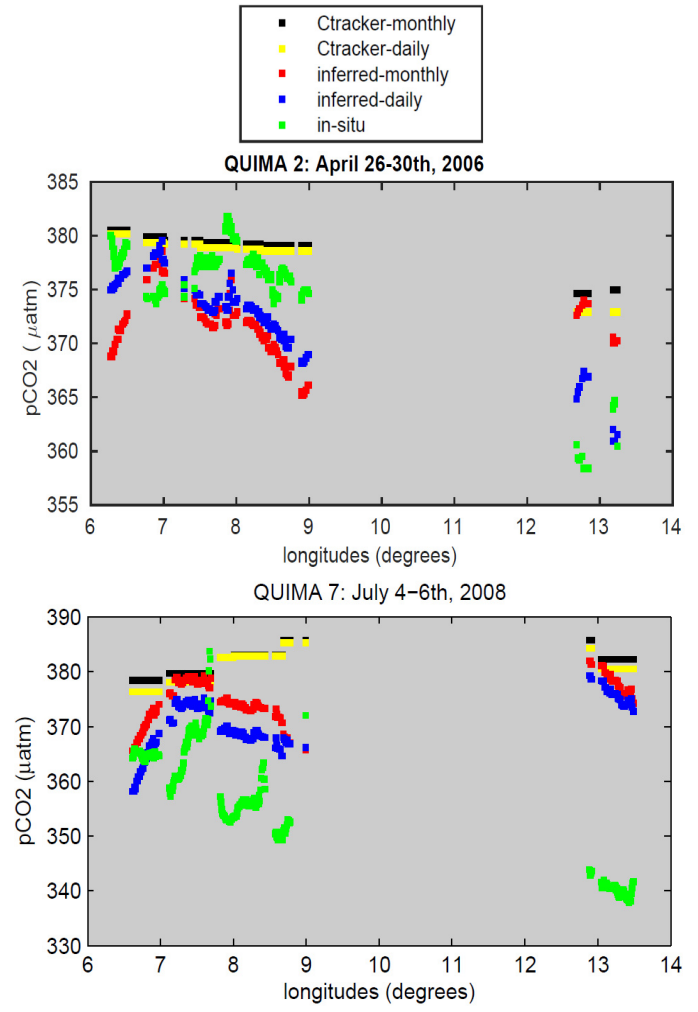

Fig. 8. Values of $\mathrm{pCO}_{2}^{\text {Ctrack }}$ derived from monthly average (black points) and daily (yellow points) versions of CarbonTracker data, $\mathrm{pCO}_{2}^{\text {infer }}$ derived from monthly CarbonTracker (red points) and daily CarbonTracker (blue points),

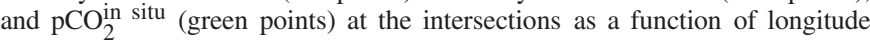
corresponding to the valid intersections during the QUIMA cruise through (a) April 26-30, 2006 and (b) July 4-6, 2008.

TABLE II

ME, AE, SDs, AND RE OF LOW-RESOLUTION $\mathrm{PCO}_{2}$ VALUES OF CARBONTRACKER AND TAKAHASHI2009 AND $\mathrm{PCO}_{2}$ VALUES INFERRED AT SUPER-RESOLUTION WITH RESPECT TO VAlues OF $\mathrm{PCO}_{2}$ Measurements DuRING THE QUIMA2006/QUIMA2008 CRUISES IN THE BENGUELA REgION

\begin{tabular}{|l|c|c|c|}
\hline & daily-CT2013 & monthly-CT2013 & C-Takahashi \\
\hline $\mathrm{N}^{\circ}$ valid intersections & 1928 & 1928 & 6497 \\
\hline$M E_{L R}(\mu a \mathrm{tm})$ & 12.76 & 12.36 & 4.19 \\
\hline$M E_{\text {infer }}(\mu \mathrm{atm})$ & 2.39 & 3.43 & -0.58 \\
\hline$A E_{L R}(\mu \mathrm{atm})$ & 18.56 & 19.36 & 14.46 \\
\hline$A E_{\text {infer }}(\mu \mathrm{atm})$ & 14.31 & 16.64 & 10.91 \\
\hline$S D_{L R}(\mu \mathrm{atm})$ & 11.13 & 11.35 & 9.89 \\
\hline$S D_{\text {infer }}(\mu \mathrm{tm})$ & 8.38 & 9.94 & 8.64 \\
\hline$R E_{L R}$ & 0.051 & 0.051 & 0.041 \\
\hline$R E_{\text {infer }}$ & 0.035 & 0.042 & 0.044 \\
\hline \hline
\end{tabular}

of 1928 intersections are used in the computations. The $\mathrm{AE}$ is smaller in both cases of $\mathrm{pCO}_{2}^{\text {infer }}$ (14.31 and $16.64 \mu \mathrm{atm}$ when inferring from daily and monthly CarbonTracker, respectively) than that of the corresponding $\mathrm{pCO}_{2}^{\text {Ctrack }}$ (18.56 and $19.36 \mu \mathrm{atm}$, respectively). Furthermore, the $\mathrm{AE}$ for the case of the $\mathrm{pCO}_{2}^{\text {infer }}$ derived from the daily Carbontracker is only $\sim 2 \mu \mathrm{atm}$ smaller than that of monthly CarbonTracker. The values of $\mathrm{pCO}_{2}^{\text {Ctrack }}$ are, in average, larger than $\mathrm{pCO}_{2}^{\text {in situ }}$ for both daily and monthly CarbonTracker cases $\left(\mathrm{ME}_{\mathrm{LR}}=12.76\right.$ and $12.36 \mu \mathrm{atm}$, respectively), while the 


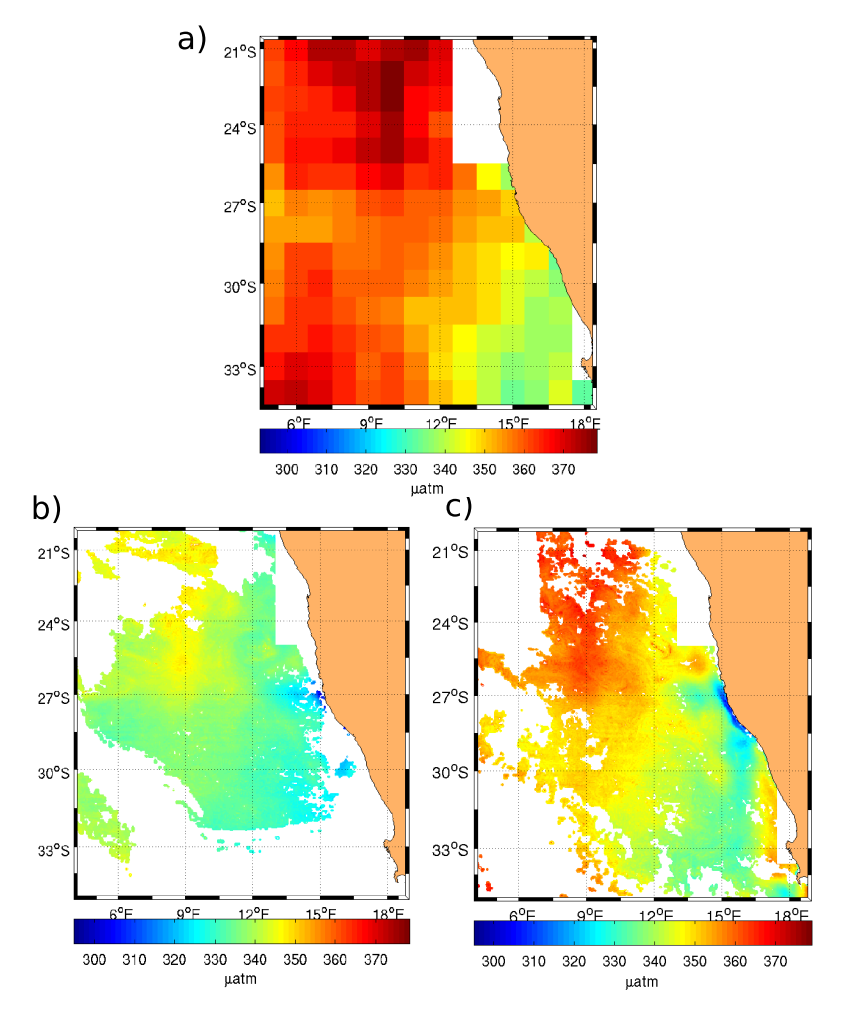

Fig. 9. Maps of (a) ocean $\mathrm{pCO}_{2}$ at the spatial resolution of $1^{\circ} \times 1^{\circ}$ derived from C-Takahashi data from September, (b) inferred $\mathrm{pCO}_{2}$ at super-resolution $\left(1 / 32^{\circ}\right)$ derived from OSTIA SST, GLOBCOLOUR-GSM Chl-a, and low resolution $\mathrm{pCO}_{2}$ derived from monthly Takahashi for September 21, 2008, and (c) inferred $\mathrm{pCO}_{2}$ at super-resolution $\left(1 / 32^{\circ}\right)$ derived from OSTIA SST, GLOBCOLOUR-GSM Chl-a, and low resolution $\mathrm{pCO}_{2}$ derived from monthly Takahashi for September 30, 2008.

differences between $\mathrm{pCO}_{2}^{\text {infer }}$ and $\mathrm{pCO}_{2}^{\text {in situ }}$ compensate each other $\left(\mathrm{ME}_{\text {infer }}=2.39\right.$ and $3.43 \mu \mathrm{atm}$, respectively). In both cases, $\mathrm{ME}_{\mathrm{LR}}$ and $\mathrm{ME}_{\text {infer }}$ are positive, meaning that $\mathrm{pCO}_{2}^{\text {Ctrack }}$ and $\mathrm{pCO}_{2}^{\text {infer }}$ are overestimated. Finally, although the RE is slightly larger in the case of the $\mathrm{pCO}_{2}^{\text {infer }}$ obtained from monthly CarbonTracker than using daily maps, these errors are low in both cases, only a $0.05 \%$.

To compare the dispersion of the mean values of $\mathrm{AE}_{\mathrm{LR}}$ and $\mathrm{AE}_{\text {infer }}$, we compute their corresponding standard deviations (SDs), $\mathrm{SD}_{\mathrm{LR}}$ and $\mathrm{SD}_{\text {infer, }}$, respectively (see Table II). In all cases, SDs are not very significant and the distribution of the errors is narrow. In the case of low resolution $\mathrm{pCO}_{2}$ the SDs is around $2 \mu \mathrm{atm}$ larger than for the inferred high resolution, and $1.5 \mu \mathrm{atm}$ larger for the case of using monthly products.

2) Inference of Daily Super-Resolution $\mathrm{pCO}_{2}$ Using Monthly Climatology Ocean pCO $\mathrm{CO}_{2}$ From Takahashi et al. [18]: In this section, we use as input data the monthly Takahashi climatology of ocean $\mathrm{pCO}_{2}$ (see Section II-C for more details). One snapshot of this product for September in the Benguela region is shown in Fig. 9(a), and the inferred high-resolution $\mathrm{pCO}_{2}$ derived from this data and for two different days in September is shown in Fig. 9(b) and (c). This figure shows that we obtain different inferred $\mathrm{pCO}_{2}$ using the same low resolution $\mathrm{pCO}_{2}$, since the proxy of the $\mathrm{SEs}$ of $\mathrm{pCO}_{2}$ is the linear combination of the SE of daily SST and Chl-a and low resolution $\mathrm{pCO}_{2}$ [see (4)]. This is also an evidence of how

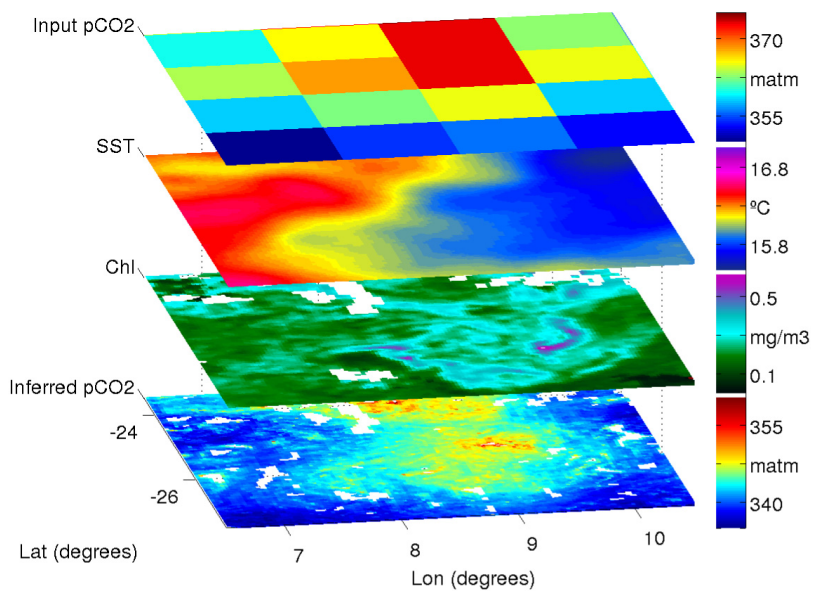

Fig. 10. Zoomed-in view of the input monthly low resolution C-Takahashi $\mathrm{pCO}_{2}$ field at (Top) $1^{\circ} \times 1^{\circ}$, (Top middle) SST, (Bottom middle) Chl-a, and (Bottom) superresolution ocean $\mathrm{pCO}_{2}$ at the spatial resolution of $1 / 32^{\circ}$ inferred using the three data sets on the top, corresponding to September 21, 2006.

the extra information of the structure details provided by the high-resolution maps of SST and Chl-a is properly captured by the cascading methodology. In addition, one can appreciate that for C-Takahashi product, the coastal coverage is increased with respect to CarbonTracker, and since sections of the cruise transects are coastal, we get a larger number of points for the validation analysis.

To observe the details of the structures in the spatial distribution of the reconstructed $\mathrm{pCO}_{2}$ values at high-resolution $\mathrm{pCO}_{2}$ introduced through the cascade methodology, a zoomedin snapshot of inferred $\mathrm{pCO}_{2}$, including a part of the transect of cruise used in the validation in the region of study, is shown in Fig. 10 (bottom). The spatial variability of $\mathrm{pCO}_{2}$ is noticeably increased in the inferred $\mathrm{pCO}_{2}$ compared with the original coarser $\mathrm{pCO}_{2}$ shown in Fig. 10 (top). One can observe that the small-scale features present in the Chl-a and SST field are introduced in the inferred $\mathrm{pCO}_{2}$ via microcanical cascade. The small-scale structures in the $\mathrm{pCO}_{2}$ field captured by the cruise measurements (see Fig. 11) are also introduced by the common turbulent feature shared with SST and Chl-a multifractal hierarchy.

The longitudinal comparison of $\mathrm{pCO}_{2}^{\text {Takah }}$ and the corresponding $\mathrm{pCO}_{2}^{\text {infer }}$ values with in situ observations is shown in Fig. 11. Most of the inferred $\mathrm{pCO}_{2}$ values approximate better in situ observations than $\mathrm{pCO}_{2}^{\text {Takah }}$. It can be seen that for the intersections located in coastal regions (longitudes larger than $12^{\circ} \mathrm{E}$ ), the values of inferred $\mathrm{pCO}_{2}$ are close to the in situ measurement values.

In general, values of $\mathrm{pCO}_{2}$ obtained from the inference methodology developed here are improved, as it can be seen in Fig. 12(a) showing the scatter plot using all the values in the intersections with in situ measurements during 2006 and 2008. Most of the points of inferred high-resolution $\mathrm{pCO}_{2}$ versus in situ $\mathrm{pCO}_{2}$ (red points) are closer to the diagonal straight line than those of the original low resolution $\mathrm{pCO}_{2}^{\text {Takah }}$ versus in situ $\mathrm{pCO}_{2}$ (blue points). This figure shows that the correlation is more satisfactory for inferred $\mathrm{pCO}_{2}$ 

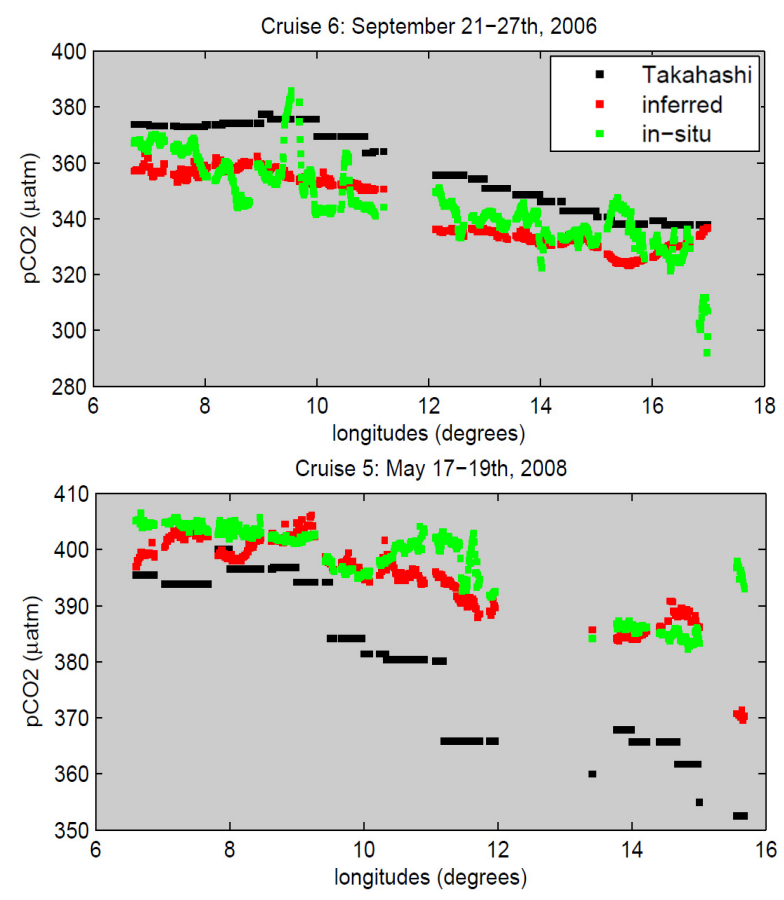

Fig. 11. Values of Takahashi $\mathrm{pCO}_{2}$ (black points), inferred $\mathrm{pCO}_{2}^{\text {infer }}$

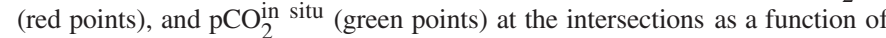
longitude corresponding to the valid intersections during the QUIMA cruise through (Top) September 21-27, 2006 and (Bottom) July 4-6, 2008.

than for $\mathrm{pCO}_{2}^{\text {Takah }}$, since there are more points of inferred $\mathrm{pCO}_{2}$ versus $\mathrm{pCO}_{2}^{\text {in situ }}$ closer to the diagonal straight line

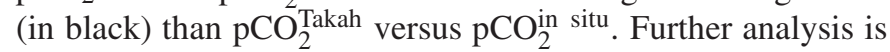
addressed performing a regional characterization of the impact of the cascade on the inference plotting in Fig. 12(b) inferred

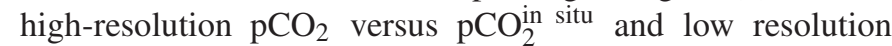
$\mathrm{pCO}_{2}^{\text {Takah }}$ versus $\mathrm{pCO}_{2}^{\text {in situ }}$ with points colored by longitude. One can appreciate that the difference between points close to the coast with those in the open ocean is significant. If we look at the scatter plot shown in Fig. 12(b), one can see that the values of inferred $\mathrm{pCO}_{2}$ in the coastal regions (longitudes greater than $12^{\circ} \mathrm{E}$ ) (red cross) are closer to the diagonal straight line than the coastal values of $\mathrm{pCO}_{2}^{\text {Takah }}$ (red circles). Thus, the cross-scale propagation of the smallscale features contained in SST and Chl-a images by the cascade is improving the values of Takahashi $\mathrm{pCO}_{2}$ in coastal regions. It can be explained because of the presence of more and stronger structures of Chl-a and SST close to the coast produced by upwelling processes and phytoplankton blooms. Thus, the resulting manifolds unveiled by the SEs in the upwelling region (see Fig. 15) have more impact on the inferring computation as required by the multiscale method.

Although a comparison between different methodologies is not the focus of this paper, we have performed some computations to show differences between our method and the conventional interpolation methods. First of all, it is worth to note that we are not doing here interpolation of missing gaps that Kriging or cubic spline would do. On the contrary, our methodology produces higher resolution products based on small-scale physical processes provided by other variables
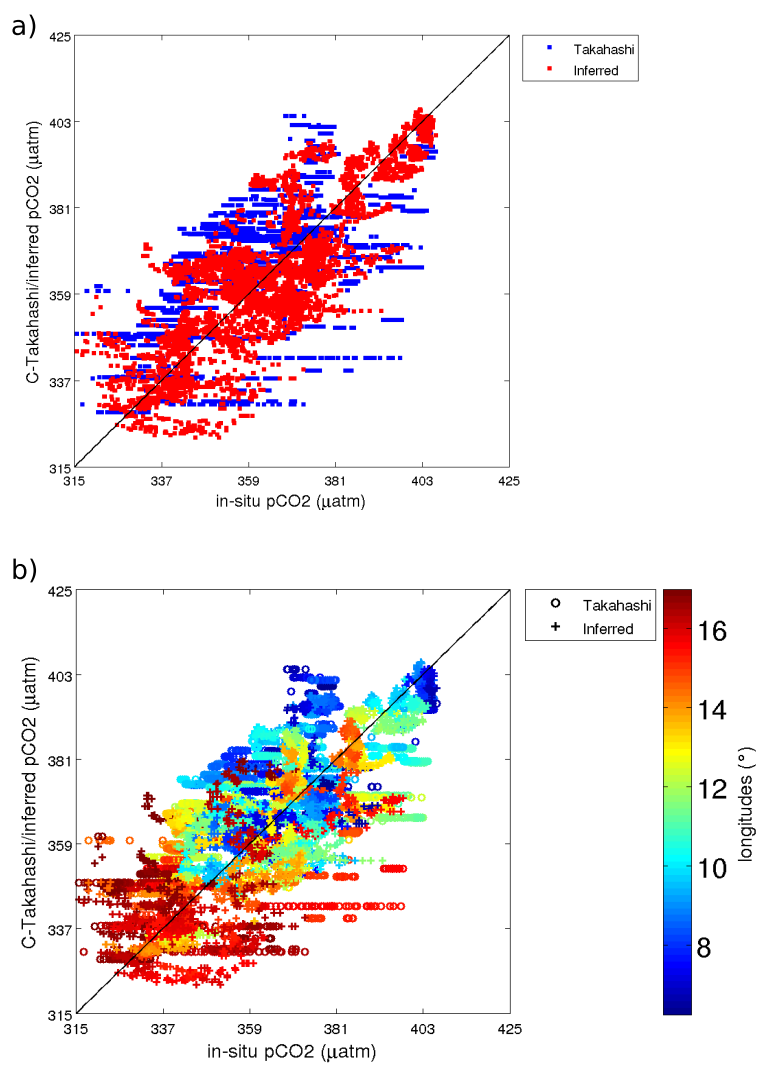

Fig. 12. (a) Scatter plot of values of Takahashi $\mathrm{pCO}_{2}$ versus $\mathrm{pCO}_{2}^{\text {in situ }}$ values (blue points) and the corresponding inferred $\mathrm{pCO}_{2}^{\text {infer }}$ versus $\mathrm{pCO}_{2}^{\text {in situ }}$ (red points) for all the cruises in 2006 and 2008. (b) Same as (a) but colored as a function of the longitude and using circles for Takahashi $\mathrm{pCO}_{2}$ versus $\mathrm{pCO}_{2}^{\text {in situ }}$ and crosses for the inferred $\mathrm{pCO}_{2}$ versus $\mathrm{pCO}_{2}^{\text {in situ }}$.

at high resolution to incorporate them in the lower resolution products. We have compared the output of our algorithm with the results of computing cubic spline and linear interpolation of the low resolution $\mathrm{pCO}_{2}$ into the high-resolution grid.

In order to provide a quantification of the difference between the three methods, we compare the values of the $\mathrm{pCO}_{2}$ field obtained from these methods with in situ measurements along the longitudinal transects of the QUIMAVOS cruises in 2006 and 2008 computing the statistical errors defined in Appendix A (see Table III). Even when the contours of the $\mathrm{pCO}_{2}$ structures are better defined by the spline cubic interpolation than the linear interpolation (not shown), the cubic spline interpolation is not able to extract the finer scale structures inferred by our methodology. Values of $\mathrm{pCO}_{2}$ obtained from linear interpolation are always very close to the original low resolution. The same happens with spline interpolation but with large separations due to border effects induced near the coast. We obtain the larger mean $\mathrm{AE}$ of $27.3 \mu \mathrm{atm}$ for the spline method, likely due to the border effect produced by the spline interpolation, which generates unwanted values near the coast, following for the lower resolution $\mathrm{pCO}_{2}(21.9 \mu \mathrm{atm})$, then linear interpolation $(21.8 \mu \mathrm{atm})$, and finally, the values $\mathrm{pCO}_{2}$ closest to in situ data are those obtained using the multiscale method (14.5 $\mu \mathrm{atm})$. 
TABLE III

ME, AE, AND RE OF THE LOW-RESOLUTION $\mathrm{PCO}_{2}$ VALUES AND High-RESOLUTION $\mathrm{PCO}_{2}$ VALUES OBTAINED FROM LiNEAR INTERPOLATION, CUBIC SPLINE AND USING THE Microcanonical Multifractal Cascade Method, With RESPECT TO VALUES OF PCO 2 MEASUREMENTS DURING THE QUIMA2006/QUIMA2008 CRUises in THE BENGUEla REgion

\begin{tabular}{|l|c|c|c|c|}
\hline & Low resolution & Linear Interp & Cubic Spline & Inferred \\
\hline $\mathrm{N}^{\circ}$ valid intersections & 1623 & 1623 & 1623 & 1623 \\
\hline$M E(\mu a t m)$ & 4.7 & 4.3 & 8.6 & -0.4 \\
\hline$A E(\mu \mathrm{atm})$ & 21.9 & 21.8 & 27.3 & 14.5 \\
\hline$R E$ & 0.061 & 0.058 & 0.078 & 0.04 \\
\hline \hline
\end{tabular}
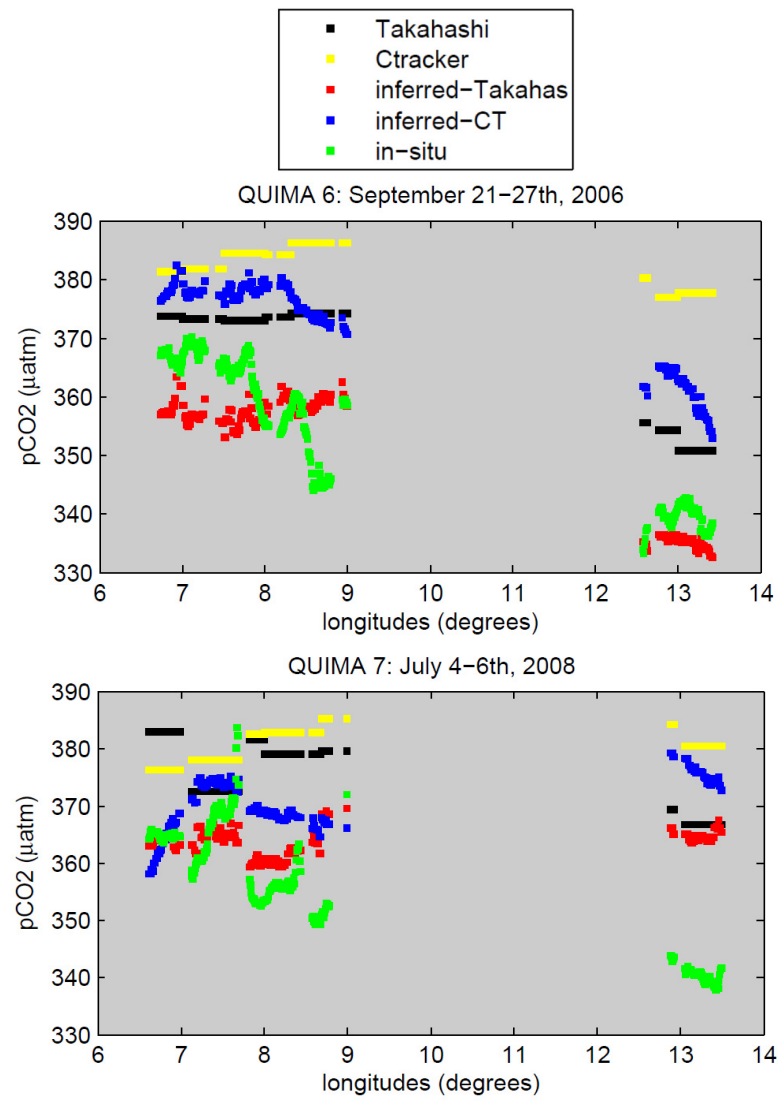

Fig. 13. Values of Takahashi $\mathrm{pCO}_{2}$ (black points), CarbonTracker $\mathrm{CT} 2013 \mathrm{pCO}_{2}$ (yellow points), inferred $\mathrm{pCO}_{2}$ from C-Takahashi (red points),

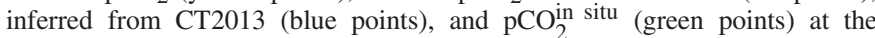
intersections as a function of longitude corresponding to the valid intersections during the QUIMA cruise through (Top) September 21-27, 2006 and (Bottom) May 17-19, 2008.

Then, we analyze the difference between the results obtained from CT2013 and C-Takahashi comparing the low resolution and the inferred $\mathrm{pCO}_{2}$ values for the two products with the in situ observations. The longitudinal profiles plotted in Fig. 13 show that the values of inferred Takahashi $\mathrm{pCO}_{2}$ are closer to the in situ observations than those reconstructed from CT2013. Indeed, if we plot the values of the reconstructed $\mathrm{pCO}_{2}$ using daily CarbonTracker versus in situ $\mathrm{pCO}_{2}$ and reconstructed $\mathrm{pCO}_{2}$ using monthly Takahashi climatology at the same points (see Fig. 14), it can be seen that the tendency to be better aligned with the diagonal straight line is clearer

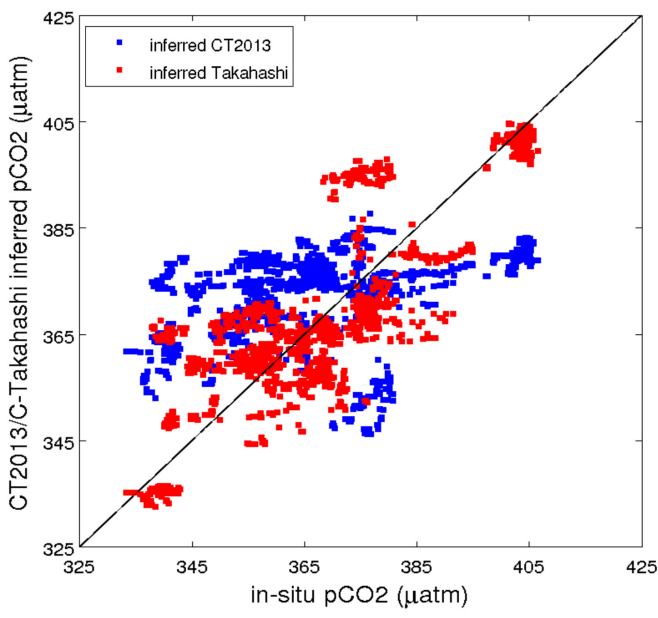

Fig. 14. Scatter plot of values inferred Takahashi $\mathrm{pCO}_{2}$ versus $\mathrm{pCO}_{2}^{\text {in situ }}$ values (red points) and inferred Ctracker $\mathrm{pCO}_{2}^{\text {infer }}$ versus $\mathrm{pCO}_{2}^{\text {in }}$ situ (blue points) for all the cruises in 2006 and 2008.

TABLE IV

ME, AE, SDs, AND RE OF LOW-RESOLUTION $\mathrm{PCO}_{2}$ VALUES OF CARBONTRACKER AND TAKAHASHI2009 AND PCO 2 VALUES INFERRED AT SUPER-RESOLUTION WITH RESPECT TO VALUES OF $\mathrm{PCO}_{2}$ MEASUREMENTS DURING THE QUIMA2006/QUIMA2008 CRUISES IN THE BENGUELA REgION AT THE SAME INTERSECTIONS OF THE SAMPLE

\begin{tabular}{|l|c|c|c|}
\hline & daily-CT2013 & monthly-CT2013 & C-Takahashi \\
\hline $\mathrm{N}^{\circ}$ valid intersections & 1762 & 1762 & 1762 \\
\hline$M E_{L R}(\mu \mathrm{atm})$ & 10.89 & 11.21 & 5.59 \\
\hline$M E_{\text {infer }}(\mu \mathrm{atm})$ & 1.84 & 5.24 & -1.37 \\
\hline$A E_{L R}(\mu \mathrm{atm})$ & 17.13 & 19.87 & 15.64 \\
\hline$A E_{\text {infer }}(\mu \mathrm{atm})$ & 13.59 & 17.74 & 11.05 \\
\hline \hline
\end{tabular}

for the points of inferred $\mathrm{pCO}_{2}$ using C-Takahashi than those of inferred $\mathrm{pCO}_{2}$ using CT2013.

To finish this section, we compute the statistical errors of the $\mathrm{pCO}_{2}^{\text {Takah }}$ and the corresponding inferred $\mathrm{pCO}_{2}$ values over all the intersections with in situ observations found during 2006 and 2008 (see the third column of Table II). First, we can see that the number of intersections for C-Takahashi is $236 \%$ larger than those for C-Tracker because of the coastal coverage. The $\mathrm{AE}$ for $\mathrm{pCO}_{2}^{\text {Takah }}$ and the corresponding $\mathrm{pCO}_{2}^{\text {infer }}$ (14.46 and $10.91 \mu \mathrm{atm}$, respectively) is smaller than when using daily CarbonTracker and monthly CarbonTracker data. Using $\mathrm{pCO}_{2}$ from Takahashi, the $\mathrm{AE}$ of the inferred $\mathrm{pCO}_{2}$ is decreased by $33 \%$ with respect to CarbonTracker. The same happens for the $\mathrm{AE}$ of the low resolution $\mathrm{pCO}_{2}$. Therefore, the better the input of $\mathrm{pCO}_{2}$ at low resolution is, the better the inference of super-resolution $\mathrm{pCO}_{2}$ is. Similar values of the errors have been found when comparing the reconstructed $\mathrm{pCO}_{2}$ from the two low-resolution products with the in situ measurements at the same intersections of the sample (Table IV). The SDs of the C-Takahashi and inferred AEs, SD, with the values of 9.89 and $8.64 \mu \mathrm{atm}$, are also smaller than those of CarbonTacker. This suggests that even removing the strong binning and strong gradients across the raw data of CarbonTracker fluxes of $\mathrm{pCO}_{2}$, the quality of 
Carbontracker is still lower than the Takahashi climatology product.

\section{CONCLUSION}

This paper shows how a new methodology based on the common multifractal features of oceanic variables is able to properly infer daily oceanic $\mathrm{pCO}_{2}$ maps at high resolution using monthly averages of CarbonTracker $\mathrm{pCO}_{2}$ at low resolution. Results are even better when we use monthly Takahashi climatology of $\mathrm{pCO}_{2}$ at low resolution. We have found out that the $\mathrm{AE}$ of the daily inferred $\mathrm{pCO}_{2}$ at super-resolution $\left(1 / 32^{\circ}\right)$ from monthly climatology Takahashi $\mathrm{pCO}_{2}$ at low spatial resolution $\left(1^{\circ}\right)$ is $5 \mu \mathrm{atm}$ smaller, in average, than that of the inferred $\mathrm{pCO}_{2}$ from daily CarbonTracker. The method has been shown to be robust when remote sensing data are used as input data; the better the input data are, the better the inference is. This is a very promising result and opens up new possibilities for dimethylsulfide inference and global assessment of $\mathrm{pCO}_{2}$, which is only available presently as monthly products. It has been proven that the methodology presented here yields the improved values of $\mathrm{pCO}_{2}$ at points near the coast in the Benguela upwelling system. This result can be used to a better characterization of relevant coastal regions, such as the four eastern upwelling systems. It could help refining the quantification of regional contribution to the global balance of greenhouse gases (GHGs).

Because of the high degree of complexity of the algorithm and due to the nonlinearity of the inference processes, the method is subject to be more sensitive to source of noise. For instance, the resulting high-resolution $\mathrm{pCO}_{2}$ maps depend on the quality of the original input data. Some satellite products use interpolation schemes to merge data from different sensors generating spurious data which could introduce artifacts in the computation of the singularity structures. Also, in this paper, we used an approach that is a first approximation of the functional relationship between the some oceanic variables, namely, SST, Chl-a, and $\mathrm{pCO}_{2}$ through multilinear relation between their corresponding singularity structures. Other more complex functional relationships and weighted regression coefficients, which are expected to reduce the noise, will be tested in a future work. In addition, preprocessing data focused on filling gaps in the satellite images from cloud coverage could improve the final output. In next studies, we will apply the method described in [7] on physics variables to fill the missing data produced by clouds.

The knowledge of the small-scale variability of GHGs fluxes will become relevant due to the great importance of the smallscale processes to understand global ocean properties. Thus, this paper represents an improvement of understanding and quantification at different spatiotemporal scales of relevant physical and biogeochemical variables in the air/sea interaction processes that play an important role in weather and climate.

\section{APPENDIX A}

\section{Statistical Quantities Used in the Validation}

The following quantities have been used to compare quantitatively the input and output oceanic $\mathrm{pCO}_{2}$ of our
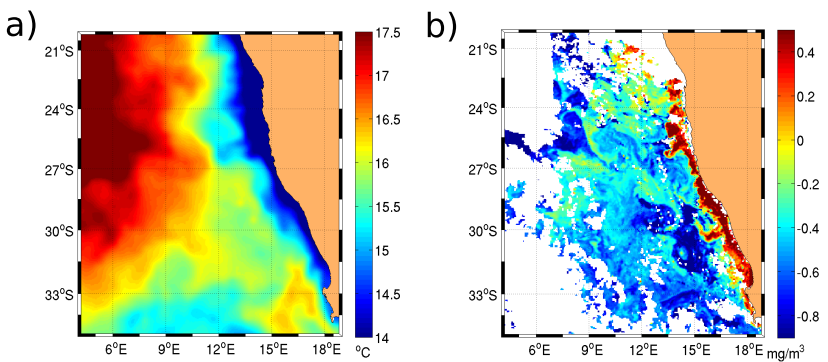

c)
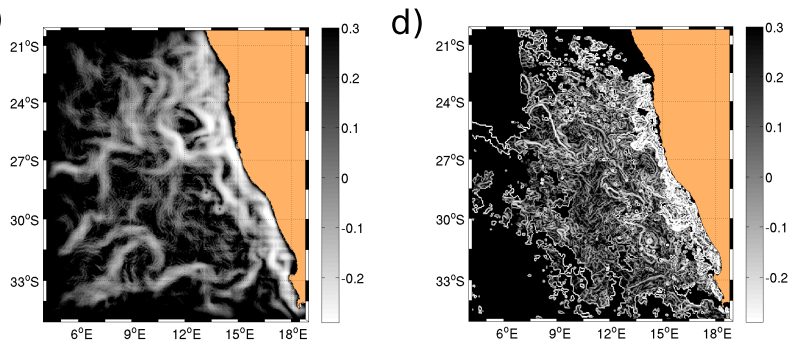

Fig. 15. (a) Snapshot of OSTIA SST field corresponding to September 30, 2008 , regridded at $1 / 32^{\circ}$ of spatial resolution from GSM GLOBCOLOUR. (b) Snapshot of Chl-a field corresponding to September 30, 2008, regridded at $1 / 32^{\circ}$ of spatial resolution. (c) and (d) Spatial distribution of SEs of the SST and Chl-a plotted in (a) and (b), respectively.

methodology, $\mathrm{pCO}_{2}^{\mathrm{LR}}$ and $\mathrm{pCO}_{2}^{\text {infer }}$, respectively, with in situ measurements $\mathrm{pCO}_{2}^{\text {in situ }}$.

1) $M E$ : Average over all the intersections of the difference between $\mathrm{pCO}_{2}$ at low resolution, $\mathrm{pCO}_{2}^{\mathrm{LR}}$ (either $\mathrm{pCO}_{2}^{\text {Ctrack }}$ or $\left.\mathrm{pCO}_{2}^{\text {Takah }}\right), \mathrm{pCO}_{2}^{\text {infer }}$ and $\mathrm{pCO}_{2}^{\text {in situ }}$ at the same intersection $i$

$$
\begin{aligned}
\mathrm{ME}_{\mathrm{LR}} & =\frac{1}{N} \sum_{i=1}^{N}\left(\mathrm{pCO}_{2}^{\mathrm{LR}}(i)-\mathrm{pCO}_{2}^{\text {in situ }}(i)\right) \\
\mathrm{ME}_{\text {infer }} & =\frac{1}{N} \sum_{i=1}^{N}\left(\operatorname{pCO}_{2}^{\text {infer }}(i)-\mathrm{pCO}_{2}^{\text {in situ }}(i)\right)
\end{aligned}
$$

where $N$ is the number of intersections.

2) Mean AE: Average over all the intersections of the absolute values of the difference between $\mathrm{pCO}_{2}$ at low resolution, $\mathrm{pCO}_{2}^{\mathrm{LR}}$ (either $\mathrm{pCO}_{2}^{\text {Ctrack }}$ or $\mathrm{pCO}_{2}^{\text {Takah }}$ ) or $\mathrm{pCO}_{2}^{\text {infer }}$ and $\mathrm{pCO}_{2}^{\text {in situ }}$ at the same intersection

$$
\begin{aligned}
\mathrm{AE}_{\mathrm{LR}} & =\frac{1}{N} \sum_{i=1}^{N}\left|\mathrm{pCO}_{2}^{\mathrm{LR}}(i)-\mathrm{pCO}_{2}^{\text {in situ }}(i)\right| \\
\mathrm{AE}_{\text {infer }} & =\frac{1}{N} \sum_{i=1}^{N}\left|\mathrm{pCO}_{2}^{\text {infer }}(i)-\mathrm{pCO}_{2}^{\text {in situ }}(i)\right| .
\end{aligned}
$$

3) Mean RE: Average over all the intersections of the errors of the estimated values of $\mathrm{pCO}_{2}$ (CarbonTracker, C-Takahashi, or their corresponding inferred) with respect to the reference $\mathrm{pCO}_{2}$ values (in situ) at the same intersection

$$
\begin{aligned}
\mathrm{RE}_{\mathrm{LR}} & =\frac{1}{N} \sum_{i=1}^{N}\left|\frac{\mathrm{pCO}_{2}^{\mathrm{LR}}(i)-\mathrm{pCO}_{2}^{\text {in situ }}(i)}{\mathrm{pCO}_{2}^{\text {in situ }}(i)}\right| \\
\mathrm{RE}_{\text {infer }} & =\frac{1}{N} \sum_{i=1}^{N}\left|\frac{\mathrm{pCO}_{2}^{\text {infer }}(i)-\mathrm{pCO}_{2}^{\text {in situ }}(i)}{\mathrm{pCO}_{2}^{\text {in situ }}(i)}\right| .
\end{aligned}
$$




\section{APPENDIX B \\ EXAMPLE OF High-RESOLUTION SST AND CHL-A SATELLITE IMAGES}

We show in Fig. 15 an example of the satellite images of the oceanic variables, SST and Chl-a used in the inference of $\mathrm{pCO}_{2}$ and their corresponding SEs

\section{ACKNOWLEDGMENT}

The authors would like to thank the Natural Environment Research Council Earth Observation Data Acquisition and Analysis Service for supplying data for this paper. The SST OSTIA product was provided by the MetOffice (http://ghrsstpp.metoffice.com). GlobColour data (http://globcolour.info) used in this paper have been developed, validated, and distributed by ACRI-ST, France (http://hermes.acri.fr/).

\section{REFERENCES}

[1] H. Yahia, J. Sudre, C. Pottier, and V. Garçon, "Motion analysis in oceanographic satellite images using multiscale methods and the energy cascade," Pattern Recognit., vol. 43, no. 10, pp. 3591-3604, 2010.

[2] A. N. Kolmogorov, "The local structure of turbulence in incompressible viscous fluid for very large Reynolds Numbers," Proc. Math. Phys. Sci., vol. 434, pp. 9-13, 1991. [Online]. Available: http://www.jstor.org/stable/51980

[3] U. Frisch, Turbulence: The Legacy of A. N. Kolmogorov. Cambridge, U.K.: Cambridge Univ. Press, 1995.

[4] U. Frisch and G. Parisi, "On the singularity structure of fully developed turbulence," in Turbulence and Predictability in Geophysical Fluid Dynamics and ClimateDynamics, M. Gil, R. Benzi, and G. Parisi, Eds. Amsterdam, The Netherlands: North-Holland, 1985, pp. 84-88.

[5] A. V. Borges, B. Delille, and M. Frankignoulle, "Budgeting sinks and sources of $\mathrm{CO}_{2}$ in the coastal ocean: Diversity of ecosystems counts," Geophys. Res. Lett., vol. 32, p. L14601, 2005, doi: 10.1029/2005GL023053.

[6] A. Turiel, H. Yahia, and C. J. Pérez-Vicente, "Microcanonical multifractal formalism-A geometrical approach to multifractal systems: Part I. Singularity analysis," J. Phys. A, Math. Theor., vol. 41, no. 1, p. 015501, 2008.

[7] C. Pottier, A. Turiel, and V. Garçon, "Inferring missing data in satellite chlorophyll maps using turbulent cascading," Remote Sens. Environ. vol. 112, no. 12, pp. 4242-4260, 2008.

[8] J. Sudre, H. Yahia, O. Pont, and V. Garçon, "Ocean turbulent dynamics at superresolution from optimal multiresolution analysis and multiplicative cascade," IEEE Trans. Geosci. Remote Sens., vol. 53, no. 11, pp. 6274-6285, Nov. 2015.

[9] I. Hernández-Carrasco et al., "Reconstruction of super-resolution ocean $p \mathrm{CO}_{2}$ and air-sea fluxes of $\mathrm{CO}_{2}$ from satellite imagery in the southeastern Atlantic," Biogeosciences, vol. 12, no. 17, pp. 5229-5245, 2015. [Online]. Available: http://www.biogeosciences.net/12/5229/2015/

[10] E. Olmedo et al., "Improving time and space resolution of SMOS salinity maps using multifractal fusion," Remote Sens. Environ., vol. 180, pp. 246-263, Jul. 2016. [Online]. Available: http://www. sciencedirect.com/science/article/pii/S0034425716300669

[11] C. Rödenbeck et al., "Data-based estimates of the ocean carbon sink variability-First results of the Surface Ocean $p \mathrm{CO}_{2}$ Mapping intercomparison (SOCOM)," Biogeosciences, vol. 12, no. 23, pp. 7251-7278, 2015. [Online]. Available: https://www.biogeosciences. net/12/7251/2015/

[12] P. Landschützer et al., "The reinvigoration of the Southern Ocean carbon sink," Science, vol. 349, no. 6253, pp. 1221-1224, 2015.

[13] L. Gregor, S. Kok, and P. M. S. Monteiro, "Empirical methods for the estimation of Southern Ocean $\mathrm{CO}_{2}$ : Support vector and random forest regression," Biogeosciences, vol. 14, pp. 5551-5569, Dec. 2017.

[14] A. V. Borges, B. Delille, and M. Frankignoulle, "Budgeting sinks and sources of $\mathrm{CO}_{2}$ in the coastal ocean: Diversity of ecosystems counts," Geophys. Res. Lett., vol. 32, no. 14, p. L14601, 2005. [Online]. Available: http://dx.doi.org/10.1029/2005GL023053

[15] J. E. Bauer, W.-J. Cai, P. A. Raymond, T. S. Bianchi, C. S. Hopkinson, and P. A. G. Regnier, "The changing carbon cycle of the coastal ocean," Nature, vol. 504, pp. 61-70, Dec. 2013.

[16] E. Gutknecht et al., "Nitrogen transfers off Walvis Bay: A 3-D coupled physical/biogeochemical modeling approach in the Namibian upwelling system," Biogeosciences, vol. 10, pp. 4117-4135, Jun. 2013.
[17] C. J. Donlon, M. Martin, J. Stark, J. Roberts-Jones, E. Fiedler, and W. Wimmer, "The Operational Sea Surface Temperature and Sea Ice Analysis (OSTIA) system," Remote Sens. Environ., vol. 116, pp. 140-158, Jan. 2012.

[18] T. Takahashi et al., "Climatological mean and decadal change in surface ocean $p \mathrm{CO}_{2}$, and net sea-air $\mathrm{CO}_{2}$ flux over the global oceans," Deep Sea Res. II, Top. Stud. Oceanogr., vol. 56, nos. 8-10, pp. 554-577, 2009.

[19] W. Peters et al., "An atmospheric perspective on North American carbon dioxide exchange: CarbonTracker," Proc. Nat. Acad. Sci. USA, vol. 104, no. 48, pp. 18925-18930, 2007.

[20] C. Sweeney et al., "Constraining global air-sea gas exchange for $\mathrm{CO}_{2}$ with recent bomb ${ }^{14} \mathrm{C}$ measurements," Global Biogeochem. Cycles, vol. 21, no. 2, p. GB2015, 2007.

[21] R. F. Weiss, "Carbon dioxide in water and seawater: The solubility of a non-ideal gas," Mar. Chem., vol. 2, pp. 203-215, Nov. 1974.

[22] H. Gildor, E. Fredj, J. Steinbuck, and S. Monismith, "Evidence for submesoscale barriers to horizontal mixing in the ocean from current measurements and aerial photographs," J. Phys. Oceanogr., vol. 39, no. 8, pp. 1975-1983, 2009.

[23] T. Delcroix, G. Alory, S. Cravatte, T. Corrège, and M. McPhaden, "A gridded sea surface salinity data set for the tropical Pacific with sample applications (1950-2008)," Deep Sea Res. I, Oceanograph. Res. Papers, vol. 58, no. 1, pp. 38-48, 2011.

[24] C. S. Garbe and J. Vihharev, "Modeling of atmospheric transport of chemical species in the polar regions," in Proc. IEEE Int. Geosci. Remote Sens. Symp., Munich, Germany, Jul. 2012, pp. 6047-6050.

[25] T. Takahashi et al., "Global sea-air $\mathrm{CO}_{2}$ flux based on climatological surface ocean $p \mathrm{CO}_{2}$, and seasonal biological and temperature effects," Deep Sea Res. II, Top. Stud. Oceanogr., vol. 49, nos. 9-10, pp. 1601-1622, 2002.

[26] D. C. E. Bakker et al., "An update to the surface ocean $\mathrm{CO}_{2}$ Atlas (SOCAT version 2)," Earth Syst. Sci. Data, vol. 6, no. 1, pp. 69-90, 2014. [Online]. Available: https://www.earth-syst-scidata.net/6/69/2014/, doi: 10.5194/essd-6-69-2014.

[27] J. M. Santana-Casiano, M. González-Dávila, and I. R. Ucha, "Carbon dioxide fluxes in the Benguela upwelling system during winter and spring: A comparison between 2005 and 2006," Deep Sea Res. II, Top. Stud. Oceanogr., vol. 56, nos. 8-10, pp. 533-541, 2009.

[28] M. González-Dávila, J. M. Santana-Casiano, and I. R. Ucha, "Seasonal variability of $f \mathrm{CO}_{2}$ in the Angola-Benguela region," Prog. Oceanogr., vol. 83, nos. $1-4$, pp. 124-133, 2009.

[29] A. Turiel, J. Isern-Fontanet, E. García-Ladona, and J. Font, "Multifractal method for the instantaneous evaluation of the stream function in geophysical flows," Phys. Rev. Lett., vol. 95, no. 10, p. 104502, 2005.

[30] O. Pont, A. Turiel, and H. Yahia, "An optimized algorithm for the evaluation of local singularity exponents in digital signals," in Proc. 14th Int. Workshop Combinat. Image Anal. (IWCIA), in Lecture Notes in Computer Science, vol. 6636, J. K. Aggarwal, R. P. Barneva, V. E. Brimkov, K. N. Koroutchev, and E. R. Korutcheva, Eds. Madrid, Spain: Springer-Verlag, 2011.

[31] O. Pont, A. Turiel, and C. J. Pérez-Vicente, "On optimal wavelet bases for the realization of microcanonical cascade processes," Int. J. Wavelets Multiresolution Inf. Process., vol. 9, no. 1, pp. 35-61, 2011.

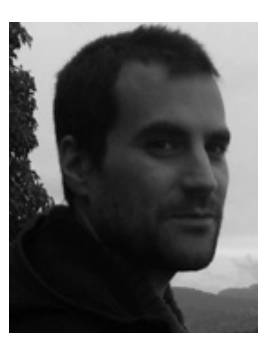

Ismael Hernández-Carrasco received the Ph.D. degree in physics from the Institute for Cross-Disciplinary Physics and Complex (Universidad de las Islas Baleares - Consejo Superior de Investigaciones Científicas), Palma, Spain, in 2013.

He was a Post-Doctoral Research Fellow with the Laboratoire d'études en géophysique et océanographie spatiales, Centre national de la recherche scientifique, Toulouse, France, supported by the European Space Agency Project OceanFlux upwelling CCN-SST (2014 and 2015). He is currently a Post-Doctoral Fellow (Juan de la Cierva) with the Balearic Islands Coastal Observing System, Palma. He has been involved in over 10 national and European projects. $\mathrm{He}$ has published over 12 papers in international journals. He has presented over 30 communications in international meetings. He has an extensive experience in new methodology coming from the dynamical systems theory and statistical physics to analyze data from satellite observations or ocean numerical models. His research interests include the nonlinear methods for signal processing and characterization of mesoscale and submesoscale structures in the ocean using Lagrangian techniques and the influence of physical processes on marine ecosystems. 


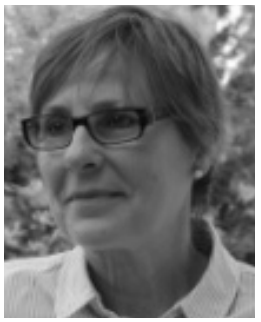

Véronique Garçon graduated in environmental sciences (energy and pollutions) from the University of Paris VII, Paris, France, in 1981.

She became a Post-Doctoral Fellow with the Massachusetts Institute of Technology, Cambridge, MA, USA, from 1982 to 1985. She was recruited as an Early Career Scientist at the Centre national de la recherche scientifique (CNRS), Toulouse, France, in 1985. She was with the Institut de Physique du Globe de Paris, Paris, and then moved down to Toulouse with a sabbatical stay at Princeton University, Princeton, NJ, USA, in 1995 and 1996. She is currently the International Chair of the Scientific Committee of the Surface Ocean Lower Atmosphere Study Project (Scientific Committee on Oceanic Research, International Commission on Atmospheric Chemistry and Global Pollution, World Climate Research Programme, and Future Earth). She has supervised 17 Ph.D. students and 18 post-doctoral fellows. She has published over 98 scientific papers in peer-reviewed journals. Her research themes within the SYSCO2 for Complex Coupled Systems Group, Laboratoire d'Etudes en Géophysique et Océanographie Spatiales, Toulouse, aim toward understanding and quantifying processes governing fluxes of carbon, oxygen, and associated biogeochemical elements in the ocean, using in situ tracers observations, remotely sensed data, coupled physical biogeochemical modeling, and data assimilation technics. She is also deeply involved in oceanic biogeochemical climatic monitoring via electrochemical sensors development.

Dr. Garçon served as a member for the French l'Institut Francais de Recherché Pour l'Exploitation de La Mer Scientific Committee for 10 years. She served in the Joint Global Ocean Flux Study Scientific Steering Committee and in many national (CNRS, National Navy, and so on), European (ESF, $\mathrm{EC}, \mathrm{EGU}$, and so on), and international scientific instances.

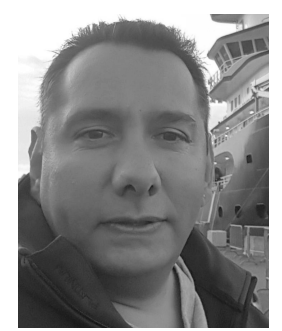

Jöel Sudre received the Ph.D. degree in physical oceanography from Paul Sabatier University, Toulouse, France, in 2013.

$\mathrm{He}$ is currently a French National Centre for Scientific Research (CNRS) Engineer with the Complex Coupled Systems (SYSCO2) Team, Laboratoire d'Etudes en Géophysique et Océanographie Spatiales, Toulouse. He is a Technical Representative with the National Institute for Earth Sciences and Astronomy/CNRS, French Ocean Data Information and Service, Toulouse. He has authored and co-authored 30 publications in international peer-reviewed journals. His research interests include physical and dynamical oceanography, image processing for oceanographic studies, and in situ and satellite ocean observing systems.

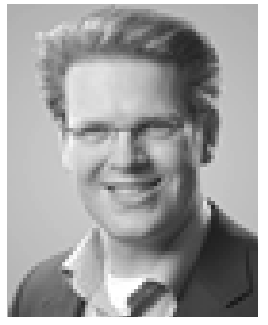

Christoph Garbe received the B.E. degree in physics from the University of Hamburg, Hamburg, Germany, in 1995, and the M.S. and Ph.D. degrees in physics and the Habilitation degree from the University of Heidelberg, Heidelberg, Germany, in 1998, 2001, and 2007, respectively.

He spent one year as a Guest Researcher at the Scripps Institution of Oceanography, San Diego, CA, USA, in 1999. From 2002 to 2004, he was the Guest Investigator at the Woods Hole Oceanographic Institution. From 2013 to 2014, he was the Substitute Chair of the Visual Sensorics and Information Processing Group at the GoetheUniversity of Frankfurt, Frankfurt, Germany. He is currently the Head of the Independent Research Group Image Processing and Modeling at the University of Heidelberg and is the Founder and the CEO of the company HD Vision Systems GmbH. His research interests include computer vision, image processing, light field imaging, pattern recognition, and environmental fluid flow.

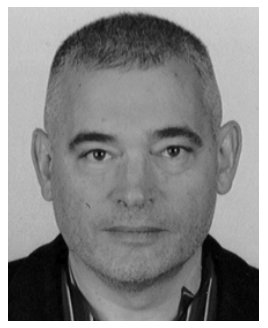

Hussein Yahia received the Doctorat de 3eme cycle degree from the University of Paris-Sud, Orsay, France, and the Habilitation à Diriger des Recherches from Paris 13 University, Villetaneuse, France.

$\mathrm{He}$ is a member of the GEOSTAT Team, Institut National de Recherche en Informatique et en Automatique (geometry and statistics in acquisition data). He has also made substantial contributions in computer graphics and image processing. He is also involved in many national, European, and international contracts, in particular with the French Spatial Agency (Centre National d'Etudes Spatiales) and the European Spatial Agency. He specializes in the nonlinear physics applications to signal processing and the analysis of complex signals and systems. He has authored or co-authored about 80 publications in international peer-reviewed journals and conferences including topranked conferences, such as the ACM Special Interest Group on Computer Graphics, the ACM Conference on Computer Vision and Pattern Recognition, and the ACM European Conference on Computer Vision. He has been supervising over $10 \mathrm{Ph} . \mathrm{D}$. students. His research interests include the nonlinear approaches to the analysis of complex signals using methods of complex systems, including sparsity, compact representations, multiresolution analysis, and optimal inference along the scales of complex signals, measures of the predictability in complex and turbulent signals, reconstruction, determination of the transitions in signals using methods of nonlinear physics, new methods for analyzing ocean dynamics from remote sensing data using nonlinear methods in signal processing (with the DYNBIO Team, Laboratoire d'Etudes en Géophysique et Océanographie Spatiales, Toulouse, France), reconstruction of the optical phase perturbated by turbulent atmosphere in astronomical imaging (adaptive optics), and new intrinsically nonlinear approaches to the analysis of heartbeat signals (with Instituts hospitalo-universitaires L'institut de rythmologie et modélisation cardiaque).

Dr. Yahia is a member of the Editorial Board of the Signal Processing and Complex Systems journals. He has given many oral invited sessions in international conferences. 